\title{
ESPECIAÇÃO TERMODINÂMICA DE METAIS TRAÇO COM SUBSTÂNCIAS HÚMICAS: O MODELO NICA- DONNAN
}

\author{
José Paulo Pinheiro,*, Adnívia Santos Costa Monteiro ${ }^{\mathrm{b}, \mathrm{c}}$, Noemie Janot ${ }^{\mathrm{a}}$, Bert Jan Groenenberga e André Henrique Rosa ${ }^{\mathrm{b}, \#}$ \\ aLIEC/UMR7360, Université de Lorraine, CNRS, 15 Avenue du Charmois, Vandoeuvre-lès-Nancy F-54501, França \\ 'Instituto de Ciência e Tecnologia, Universidade Estadual Paulista, 18087-180 Sorocaba - SP, Brasil \\ 'Instituto de Química, Universidade Estadual Paulista, 14800-060 Araraquara - SP, Brasil
}

Recebido em 07/02/2017; aceito em 05/06/2017; publicado na web em 15/08/2017

\begin{abstract}
TRACE METAL THERMODYNAMIC SPECIATION WITH HUMIC SUBSTANCES: THE NICA-DONNAN MODEL. This work presents a critical overview of the NICA-Donnan model for trace metal thermodynamic speciation with humic substances obtained from natural organic matter in soils, natural waters and anthropogenic sources. A first part covers the theoretical aspects of the model, how to obtain good experimental data and perform the modelling. A second part deals with the developments in the last decade namely the use of the generic parameters, criticism and alternatives to the electrostatic modeling, the understanding of the NICA equation and an analysis of the published data, ending with the needs and opportunities for model development.
\end{abstract}

Keywords: trace metals; speciation; humic substances; NICA; Donnan.

\section{INTRODUÇÃO}

Os metais traço desempenham um papel muito importante no ambiente, pois em sua maioria são essenciais à vida em concentrações moderadas e tóxicos em concentrações elevadas.

A análise de especiação de metais traço em águas naturais é complicado, uma vez que esses formam complexos estáveis com a enorme variedade de ligantes inorgânicos e orgânicos de pequena dimensão presentes na matriz. No meio aquático, os metais traço podem se adsorver a coloides e macromoléculas, interagir com superfícies minerais (incluindo os fenômenos de precepitação/dissolução) e micro-organismos.

Neste contexto complexo, os modelos de especiação química de metais traço com diferentes superfícies/agentes complexantes em águas naturais são a chave para a compreensão da biodisponibilidade dos metais traço no ambiente.

Para responder a este desafio têm sido desenvolvidas plataformas de modelos de especiação termodinâmica, como o Visual MinteQ, ${ }^{1}$ ECOSAT, ${ }^{2}$ PhreeQ,${ }^{3}$ WHAM $^{4}$ ou ORCHESTRA. ${ }^{5}$ Estas plataformas usam bases de dados semelhantes para a complexação de ligantes orgânicos e inorgânicos simples, residindo as diferenças nos tipos de modelos de complexação escolhidos para os coloides e macromoléculas orgânicas, partículas e superfícies minerais e interação com micro-organismos.

Dentre os complexantes presentes em águas naturais, a matéria orgânica natural (MON) é a principal responsável pela complexação dos íons metálicos. A MON apresenta um caráter polifuncional e polieletrolítico, apresentando, por isso, um conjunto de energias livres de complexação, de constantes de velocidade de formação/dissociação e de tamanhos, que controlam a biodisponibilidade, toxicidade e mobilidade dos íons metálicos no ambiente. ${ }^{6}$

\section{SUBSTÂNCIAS HÚMICAS}

As substâncias húmicas $(\mathrm{SH})$ representam a principal classe de complexantes naturais e, devido à complexidade da MON, os estudos

*e-mail: jose-paulo.pinheiro@univ-lorraine.fr

\#e-mail alternativo: ahrosa@sorocaba.unesp.br de complexação têm sido conduzidos especialmente com as SH, as quais podem ser extraídas utilizando diferentes metodologias. A extração das SH é operacional, podendo-se ainda, dependendo do estudo a ser feito, realizar o fracionamento das SH de forma a obtenção de frações com propriedades físico-químicas similares em função do $\mathrm{pH}$, por exemplo, em humina (insolúvel), ácidos fúlvicos (fração solúvel) e ácidos húmicos (solúvel em meio alcalino e insolúvel em $\mathrm{pH}$ menor que 2).

Stevenson ${ }^{7}$ no capítulo 2 e Tam ${ }^{8}$ no capítulo 4 de seus livros fazem um relato do desenvolvimento das pesquisas do húmus, sendo que a primeira publicação sobre isolamento e fracionamento de matéria orgânica de solo é atribuída ao químico e biólogo alemão Franz Karl Achard. Em 1786, ele publicou um estudo no qual extraiu matéria orgânica de uma turfa com hidróxido de potássio diluído e obteve um precipitado escuro e amorfo após acidificar a solução. O nome "ácidos húmicos" $(\mathrm{AH})$ foi atribuído por Dobereiner em 1822. Por outro lado, as substâncias húmicas aquáticas foram extraídas pela primeira vez, de uma fonte na Suécia, por Berzelius em 1806. Já a denominação "ácidos fúlvicos" (AF) foi introduzida por Oden em 1919, em um trabalho sobre a origem da cor nas águas naturais.

Desde que foi isolada a primeira amostra substâncias húmicas de solos, é comum aparecerem grandes interrogações sobre sua gênese, sua estrutura química e sua representatividade. Uma prova dessas indagações, ainda nos dias de hoje, é o artigo de Lehmman e Kleber, em 2015, na revista Nature. ${ }^{9}$

Estas questões estão intimamente ligadas não só à complexidade própria das substâncias húmicas, mas também à variabilidade resultante das diferentes origens e distintas técnicas de extração e purificação. Fica evidente que essa abrangência dificulta a comparação interlaboratorial de resultados experimentais.

Devido a esta dificuldade, na década de 1970, houve um forte movimento no sentido de estabelecimento de padrões certificados de substâncias húmicas, de forma a permitir a validação/comparação de resultados experimentais. A iniciativa foi de Patrick MacCarthy, do Colorado School of Mines, e Ronald Malcolm do US Geological Survey (USGS) ${ }^{10}$ Esse movimento levou à fundação da International Humic Substances Society (IHSS), em 1981, cujo principal objetivo foi recomendar a padronização de procedimentos para coleta, extração e purificação de ácidos húmicos e fúlvicos de solos, leonardite, turfa 
e águas naturais, bem como a disponibilização de amostras padrão destes materiais. ${ }^{11}$

Desde a sua criação, a IHSS teve marcante sucesso e implantação em nível internacional, com uma forte representação brasileira, tendo inclusive Ladislau Martin-Neto (EMBRAPA-São Carlos) como presidente entre 2010 e 2012. Atualmente, a IHSS tem sido um pilar importante da diversa comunidade científica que estuda as substâncias húmicas, promovendo sua disseminação a partir de iniciativas de intercâmbio de jovens pesquisadores/alunos de pós-graduação entre instituições mundiais, bem como organizando grupos que estudam as SH em diferentes países e uma série de conferências internacionais de sucesso. ${ }^{12}$

De fato, uma grande quantidade das medidas de interação entre metais traço e substâncias húmicas foi realizada com os materiais de referência da IHSS. Porém, ter materiais de referência não é suficiente, pois para usar modelos de especiação em plataformas de especiação genéricas é necessário que as constantes de complexação sejam intrínsecas, não podendo depender das condições do meio como o $\mathrm{pH}$, força iônica ou a presença de outros íons.

\section{Descrição da complexação de metais traço com substâncias húmicas}

O desenvolvimento de modelos de complexação intrínsecos para as substâncias húmicas representou um grande desafio devido a sua heterogeneidade química e caráter polieletrolítico. Na década de 1990 começaram a ser desenvolvidos, praticamente em paralelo, dois modelos de complexação de metais traço com ácidos húmicos e fúlvicos como representantes da matéria orgânica natural: o modelo discreto de Tipping ${ }^{13}$ e o modelo contínuo de Van Riemsdijk e Koopal (Non-Ideal Competitive Adsorption, NICA). ${ }^{16,17}$

De forma muito rápida, no desenvolvimento de ambos os modelos de complexação, tornou-se evidente a necessidade de separar a complexação química - devido à existência de diferentes grupos complexantes - da complexação física - devido às interações eletrostáticas associadas às cargas negativas da molécula. Esse processo foi feito por meio da inclusão de modelos eletrostáticos, como o de Donnan. ${ }^{18}$

Os grupos que desenvolveram estes modelos trabalharam frequentemente em conjunto e partilharam muitas vezes as bases de dados experimentais na parametrização dos respectivos modelos. Dessa forma, observou-se que, do ponto de vista de ajuste dos dados experimentais, não existe uma diferença significativa entre os modelos, pois o número de parâmetros ajustáveis é muito semelhante.

O desenvolvimento do modelo de NICA-Donnan foi marcante durante a década de 1990 e culminou com a publicação de parâmetros genéricos de complexação com ácidos fúlvicos e húmicos para o hidrogênio em $2001^{19}$ e de uma série de metais traço em 2003. ${ }^{20}$ Estes parâmetros genéricos resultaram da análise e parametrização de uma quantidade apreciável de dados experimentais, mas desde esta data o modelo de NICA-Donnan não foi alterado. Em 2005, Koopal e colaboradores publicaram uma revisão crítica do modelo de NICA-Donnan em que explicam claramente as bases teóricas e fazem um levantamento da sua utilização. ${ }^{21}$

O objetivo deste artigo é fazer uma revisão crítica da aplicação do modelo de NICA-Donnan desde 2005, contemplando as críticas e sugestões aos aspectos teóricos, a evolução do ponto de vista dos códigos de modelagem e ajuste, a utilização dos parâmetros genéricos e um levantamento das novas medidas experimentais publicadas.

\section{O MODELO DE NICA-DONNAN}

Para uma discussão mais detalhada, os leitores são referidos à revisão de $2005^{21}$ e ao material suplementar deste artigo, no qual se encontra a explicação detalhada da equação NICA.

Nesta síntese vamos seguir a sequência da metodologia experimental, ou seja, de considerar primeiro a contribuição eletrostática e em seguida, descrever a heterogeneidade química.

\section{Efeito eletrostático: o modelo de Donnan}

Os polieletrólitos naturais, como as substâncias húmicas, obtêm a sua carga primária por meio do equilíbrio de protonação. Quanto maior for a força iônica da solução maior vai ser a blindagem das cargas, e menor será o efeito eletrostático. Desta forma, o efeito da força iônica na protonação providencia uma medida do efeito eletrostático, que pode ser experimentalmente observado por comparação de titulações ácido-base em diferentes forças iônicas.

Para avaliar especificamente os efeitos eletrostáticos, é necessário conhecer a estrutura e a composição da dupla camada elétrica, a natureza e geometria das partículas, moléculas, agregados ou coloides em questão. Assim, a escolha do modelo para a dupla camada elétrica implica fazer uma série de aproximações no que diz respeito à geometria das moléculas e ao próprio potencial. Se o modelo escolhido for apropriado, então as curvas de protonação, obtidas em diferentes forças iônicas, devem fundir-se em uma só curva, a curva mestra, que refletirá a distribuição intrínseca de afinidades do íon hidrogênio (Figura 1).

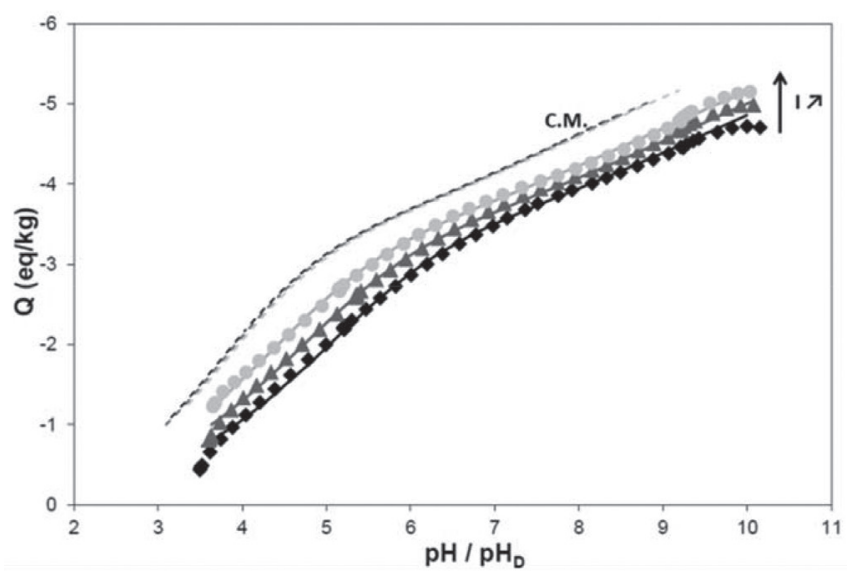

Figura 1. Exemplo de titulação ácido-base de uma amostra de ácidos húmicos em diferentes forças iônicas (símbolos) com a respectiva curva mestra (C.M., linhas tracejadas)

A aplicação do conceito de curva mestra à protonação de ácidos húmicos e fúlvicos foi introduzida em $1993^{22}$ utilizando um modelo de Poisson-Boltzmann de esferas rígidas ou cilindros, mas a partir de 1996 foi adotado um modelo de Donnan modificado, ${ }^{18}$ que continua a ser o mais utilizado atualmente.

A aproximação mais importante é que o potencial local, $\psi_{\text {loc }}$, pode ser caracterizado por apenas um valor para todas as posições de complexação, o que equivale a dizer que as cargas estão distribuídas de forma homogênea e que se negligenciam os efeitos do tamanho e forma da molécula. Apesar desta ser uma grande simplificação da realidade, torna-se necessária para poder modelar o efeito da força iônica com o menor número de parâmetros possível.

De uma forma resumida, a atividade local, , na vizinhança da posição de complexação do ligante é dada por um fator de Boltzmann:

$$
a_{i, l o c}=a_{i} \exp \left(-z_{i} F \Psi_{l o c} / R T\right)
$$

em que $a_{i}$ é a atividade no interior da solução, $\Psi_{\text {loc }}$ é o potencial característico na posição de complexação, $z_{\mathrm{i}}$ é a carga da espécie 
i, $F$ a constante de Faraday, $R$ a constante dos gases perfeitos e $T$ a temperatura.

Ao aplicar o modelo de Donnan, assume-se que o potencial local é o potencial de Donnan $\left(\Psi_{\mathrm{loc}}=\Psi_{\mathrm{D}}\right)$ e que toda a carga na molécula das substâncias húmicas, $q$ (mol carga/ $/ \mathrm{kg}$ de $\mathrm{SH})$ se encontra completamente neutralizada pela inclusão de contraíons e exclusão de coíons no volume de Donnan, $V_{\mathrm{D}}$ (in $\mathrm{L} / \mathrm{kg}$ ) segundo a equação de eletroneutralidade:

$$
q / V_{D}+\Sigma_{i} z_{i}\left(a_{i, D}-a_{i}\right)=0
$$

em que $a_{i}=a_{i, l o c}$ é a atividade do componente $i$ no volume de Donnan.

Uma das dificuldades ao resolver a equação (2) é a obtenção do valor do volume de Donnan. Na formulação original da teoria eletrostática de Donnan, que se aplica a géis, isto não é uma dificuldade, pois o $V_{\mathrm{D}}$ é o volume do gel que pode ser medido facilmente. Neste caso, devido às aproximações envolvidas na definição do modelo eletrostático, o $V_{\mathrm{D}}$ é de fato um parâmetro ajustável. Benedetti e colaboradores observaram uma relação linear entre $V_{\mathrm{D}}$ e a força iônica, $I$, e propuseram uma relação empírica para calcular o volume de Donnan: ${ }^{23}$

$$
\log V_{D}=b(1-\log I)-1
$$

em que b é um parâmetro ajustável.

Para obter os parâmetros do modelo eletrostático realizam-se titulações potenciométricas ácido-base das $\mathrm{SH}$ em pelo menos três forças iônicas (tipicamente entre 10 e $300 \mathrm{mmol} \mathrm{L}^{-1}$ ), obtendo-se por diferença entre o branco a carga específica das substâncias húmicas (em $\mathrm{C} / \mathrm{Kg}$ de $\mathrm{SH}$ ) para cada valor de $\mathrm{pH}$. Em seguida deve-se aplicar uma conversão do $\mathrm{pH}$ no interior da solução para o $\mathrm{pH}$ local na vizinhança da posição de complexação, ou seja, $p H_{l o c}=\left(-\log a_{H, l o c}\right)$, para cada uma das curvas de titulação obtidas em diferentes forças iônicas. Como as interações eletrostáticas são consideradas explicitamente no $p H_{l o c}$ e o efeito da força iônica deve desaparecer, as três curvas devem convergir em uma curva mestra (Figura 1).

Do ponto de vista de modelagem, trata-se de resolver a equação da eletroneutralidade (2) para cada ponto experimental das curvas de titulação, expressas como q.vs. $\log a_{\mathrm{i}}$, ou seja, usar um procedimento de ajuste do valor de $V_{\mathrm{D}}$ e de $\Psi_{D}$.

\section{Heterogeneidade química intrínseca: o modelo NICA}

A ideia subjacente à análise de heterogeneidade é que a complexação em um sistema heterogêneo pode ser descrita como o somatório da complexação nos ligantes individuais, para os quais a complexação é descrita por uma isoterma local, representada pelas suas frações. ${ }^{24}$

Na modelagem da complexação de sistemas heterogêneos, considera-se a isoterma global como uma integração das isotermas locais ao longo da função de distribuição contínua. A equação de complexação global é uma equação integral com a isoterma local como núcleo, conhecida como equação integral de Fredholm do primeiro tipo. Conhecendo a função de complexação global e isoterma local, esta equação é bastante difícil de resolver para obter a função de distribuição, tanto numericamente, como analiticamente. ${ }^{25}$

Para estudar a heterogeneidade das SH utiliza-se a curva mestra do hidrogênio em função do pH em um eletrólito 1:1 simples. Este é um bom ponto de partida, pois não há competição com outros íons. Note-se, por outro lado, que é difícil obter uma distribuição completa de constantes de afinidade por causa da dificuldade em titular abaixo de pH 3,5 (precipitação dos ácidos húmicos) e acima de $\mathrm{pH}$ 10,5 (erro alcalino).

Quando se efetua a derivada da curva mestra, obtém-se um espectro de afinidades aparentes para o íon hidrogênio com duas bandas semi-gaussianas com máximos a $\mathrm{p} K$ cerca de 3,5 e 8,0, as quais se associam, respectivamente, aos grupos do tipo carboxílicos e fenólicos. ${ }^{26}$

Uma das grandes vantagens da equação NICA é ser uma equação multicomponente que considera implicitamente a competição entre os diferentes cátions (incluindo o hidrogênio). Mas é preciso mencionar que uma aproximação importante do ponto de vista físico-químico é que nessa transição de complexação monocomponente para um sistema multicomponente, considera-se que as posições de complexação ativas para o hidrogênio são as mesmas que complexam os outros cátions. Como todos os cátions complexados competem pelos mesmos sítios de complexação, este fenômeno afeta tanto a isoterma local como a isoterma global.

A equação NICA, que explicita a quantidade complexada de íon $i$ (em mol/ $\mathrm{Kg}$ de $\mathrm{SH}$ ) em função da atividade de todas as espécies presentes na solução (em mol/L), é dada por: ${ }^{17}$

$$
Q_{i, T}=\left(\frac{n_{i} Q_{\max H, T}}{n_{H}}\right) \frac{\left(\widetilde{K}_{i} a_{i}\right)^{n_{i}}}{\sum_{i}\left(\widetilde{K}_{i} a_{i}\right)^{n_{i}}} \frac{\left(\sum_{i}\left(\widetilde{K}_{i} a_{i}\right)^{n_{i}}\right)^{p}}{1+\left(\sum_{i}\left(\widetilde{K}_{i} a_{i}\right)^{n_{i}}\right)^{p}}
$$

Os parâmetros são: as quantidades totais por tipo de sítios $Q_{\operatorname{maxH}, T}$ as constantes médias de complexação, $\widetilde{K}$, os parâmetros estequiométricos, $n_{i}$, e a largura da distribuição genérica por posição de complexação, $p$. Todos estes parâmetros são intrínsecos, logo, independentes das propriedades do meio como $\mathrm{pH}$, força iônica ou concentrações dos íons em solução.

Os parâmetros do modelo NICA para o hidrogênio são obtidos a partir da curva mestra para os sítios dos ácidos carboxílicos (1) e fenólicos (2), incluindo as quantidades máximas, $Q_{\max H 1, T}, Q_{\max H 2, T}$, as constantes médias de complexação, $\widetilde{K}_{H, 1}, \widetilde{K}_{H, 2}$ e dois parâmetros mistos contendo informação sobre a estequiometria e a largura de distribuição genérica, $n_{H 1} p_{1}$ e $n_{H 2} p_{2}$. Os parâmetros de largura de distribuição apenas são acessíveis a partir da equação de competição em presença de outros íons (eq. 4), não podendo ser calculados a partir da equação monocomponente para o hidrogênio (eq. 3).

Para obter os parâmetros específicos dos cátions e as larguras de distribuição realizam-se experimentos de titulação adicionando o cátion desejado a uma quantidade previamente conhecida de substâncias húmicas em uma força iônica constante. Estas titulações devem ser feitas em, pelo menos, três valores distintos de $\mathrm{pH}$ de preferência no intervalo da faixa de complexação carboxílicas e fenólicas (Figura 2).

A partir dos dados experimentais e dos parâmetros já conhecidos, procede-se o ajuste da equação NICA bimodal (eq. 4) simultaneamente para todos os pontos experimentais $\left(\log Q_{\mathrm{M}, \mathrm{T}} \mathrm{Vs} . \log a_{\mathrm{M}}\right)$ aos diferentes valores de $\mathrm{pH}$. Este procedimento de ajuste, normalmente recorrendo a métodos de mínimos quadrados, providencia os valores dos parâmetros para o íon metálico em questão, neste caso, $\widetilde{K}_{M, 1}, \widetilde{K}_{M, 2}$, $n_{M 1}$ e $n_{M 2}$, e ainda os valores de $\mathrm{p}_{1}$ e $\mathrm{p}_{2}$ característicos das substâncias húmicas, ao mesmo tempo em que a determinação dos valores de $p$ permite a obtenção dos valores de $n_{H 1}$ e $n_{H 2}$.

\section{ASPECTOS EXPERIMENTAIS}

A partir das considerações e referencial teórico, apresenta-se a seguir as condições experimentais adequadas para a execução das titulações potenciométricas e obtenção de curvas e parâmetros de complexação de interesse.

\section{As titulações ácido-base}

As titulações potenciométricas das substâncias húmicas são operações meticulosas, pois para obtenção de bons resultados deve-se 


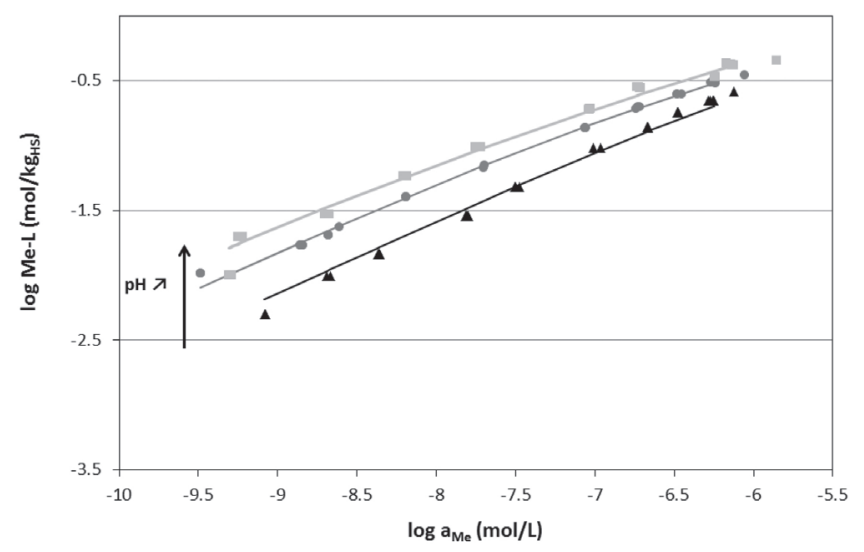

Figura 2. Exemplo de complexação de um metal $\mathrm{Me}^{2+}$ com uma amostra de ácidos húmicos obtidos para a mesma força iônica e vários $\mathrm{pH}$ com a respectiva modelização NICA

controlar cuidadosamente todo o procedimento experimental. Estas dificuldades têm a sua origem não só na natureza heterogênea das $\mathrm{SH}$, mas também na sua facilidade de agregação e desagregação, especialmente no caso dos ácidos húmicos.

Nas titulações ácido-base o limite superior é definido pelo erro alcalino do eletrodo em torno de $\mathrm{pH}$ 9,5, devendo-se manter a solução com uma purga de nitrogênio para evitar problemas de carbonatos. Estas titulações requerem a utilização de eletrodos de vidro de alta qualidade para obtenção de bons resultados em meio alcalino. No entanto, para titulações das SH esta é uma região de interesse e para minimizar esse efeito, pode-se obter a carga das SH pela subtração direta da curva de titulação da matéria húmica pelo branco, em uma titulação efetuada à mesma concentração iônica. Isto implica em titular brancos a cada força iônica e realizar as duas titulações usando exatamente as mesmas adições de volume de titulante para poder subtrair ponto a ponto, ou alternativamente interpolar matematicamente a curva do branco.

As substâncias húmicas se agregam facilmente e ao efetuar as titulações a partir de material seco, ou no caso dos ácidos húmicos, mesmo se estiver dissolvido, é conveniente desagregar bem antes de iniciar a titulação. O método mais comum é dissolver o material em hidróxido de sódio ou potássio $10^{-4} \mathrm{~mol} \mathrm{~L}^{-1}$, e em seguida ajustar a pH 10 sob atmosfera de nitrogênio para evitar reações de oxidação/ condensação e esperar cerca de 1 h. Voltar a ajustar a pH 10 e deixar durante a noite.

A escolha das forças iônicas para efetuar as titulações também é importante, pois abaixo de $3 \mathrm{mmol} \mathrm{L}^{-1}$ a resposta dos eletrodos de $\mathrm{pH}$ é muito lenta, demorando muito tempo para atingir o equilíbrio, e acima de $300 \mathrm{mmol} \mathrm{L}^{-1}$, frequentemente se observa problemas de precipitação para os ácidos húmicos.

Como é muito importante conhecer rigorosamente a variação de carga com a variação de força iônica, normalmente encadeiam-se titulações em diferentes forças iônicas na mesma solução, fazendo titulações de retorno, adicionando o sal na mesma solução e continuando o ciclo.

Devido à heterogeneidade das substâncias húmicas, para a modelagem é necessário um conjunto elevado de pontos experimentais, sendo frequente para uma titulação entre $\mathrm{pH}$ 3,5 e 10,5 ter várias dezenas. Isto conduz a titulações longas, pois adicionalmente é crítico garantir que se atinge o equilíbrio para cada adição de titulante.

A experiência mostra que nestas titulações sempre são observadas uma deriva para $\mathrm{pH}$ mais ácido na titulação com base e uma histerese entre a titulação direta (com base) e a de retorno (com ácido). ${ }^{27}$ Assim, é necessário definir critérios de deriva rigorosos, da ordem de 0,05 $\mathrm{mV} / \mathrm{min}$, com tempos de medida mínimos de 2 min e máximos na ordem de 15 a 20 min por ponto. Como os brancos devem ser feitos nas mesmas condições, temos titulações que variam entre horas até cerca de um dia, para as mais demoradas.

Devido a estes condicionamentos, é virtualmente impossível efetuar estas titulações manualmente, sendo necessário um titulador automático, de preferência com três autoburetas, uma de ácido, outra de base e uma terceira para o sal.

Em resumo, uma titulação de $\mathrm{pH}$ efetua-se da seguinte forma:

1) Calibração do eletrodo de $\mathrm{pH}$ com pelo menos três tampões: 4 , 7 e 10

2) Titulações do branco:

i) colocar um volume inicial a $\mathrm{pH} 3$ para os fúlvicos (AF) e 3,5 para os húmicos $(\mathrm{AH})$ à força iônica mais baixa;

ii) titular com $\mathrm{NaOH}(\mathrm{ou} \mathrm{KOH})$ tipicamente $0,1 \mathrm{~mol} \mathrm{~L}^{-1}$ até $\mathrm{pH}$ 10,5 ;

iii) titular com ácido $\mathrm{HNO}_{3}$ (ou $\mathrm{HCl}$ ) tipicamente $0,1 \mathrm{~mol} \mathrm{~L}^{-1}$ até ao $\mathrm{pH}$ inicial;

iv) adicionar sal $\mathrm{NaNO}_{3}$ (ou $\mathrm{KCl}$ ) $1,0 \mathrm{~mol} \mathrm{~L}^{-1}$ até atingir a força iônica intermédia;

v) titular com base até $\mathrm{pH}$ 10,5;

vi) titular com ácido até ao $\mathrm{pH}$ inicial;

vii) adicionar sal até atingir a força iônica mais elevada;

viii) titular com base até $\mathrm{pH}$ 10,5;

ix) titular com ácido até ao $\mathrm{pH}$ inicial.

3) Titulação das substâncias húmicas:

x) colocar na célula de titulação uma concentração conhecida de substâncias húmicas bem dispersa no mesmo volume e pH inicial e força iônica mais baixa que o branco inicial.

Repetir as etapas de ii a ix feitas para o branco.

\section{Determinação da concentração do íon metálico livre}

Para a modelagem com NICA-Donnan, é necessário ter a variação da atividade do metal complexado (em mol/Kg de $\mathrm{SH}$ ) em função da atividade do metal livre. Como se assume que a contribuição eletrostática se obtém da modelagem do hidrogênio, trabalha-se a força iônica constante (normalmente entre 10 e $100 \mathrm{mmol} \mathrm{L}^{-1}$ ), sendo possível converter atividades em concentrações.

Os experimentos típicos são a titulação de uma quantidade conhecida de SH, com o íon metálico de interesse, em uma força iônica constante e vários valores de $\mathrm{pH}$. Conhecendo o valor da concentração total de íon metálico, a concentração do íon metálico livre é medida e o balanço de massa é utilizado para obter a concentração de metal complexado pelas SH. O maior problema é que do ponto de vista experimental não há muitas técnicas capazes de medir a concentração de íons metálicos livres nos níveis de concentrações de metais traço em águas naturais.

Pesavento et al..$^{28}$ apresentaram uma revisão sobre métodos analíticos de determinação de concentração de íon metálico livre, fração de espécies lábeis e capacidade de complexação em águas naturais. Esta revisão separa técnicas eletroanalíticas compreendendo voltametria de redissolução anódica (ASV, do inglês Anodic Stripping Voltammetry), voltametria de redissolução por troca de ligante competitiva (CLE-SV, do inglês Competitive Ligand Exchange-Stripping Voltammetry), cronopotenciometria de redissolução (SCP, do inglês Stripping Chronopotentiometry), redissolução nernstiana na ausência de gradientes (AGNES, do inglês Absence of Gradients and Nernstian Equilibrium Stripping) e microeletrodo integrado a gel (GIME-VIP, do inglês Gel Integrated Microelectrode), e outras técnicas envolvendo microseparações, tais como a técnica de membrana Donnan (DMT, do inglês Donnan 
Membrane Technique), gradiente difusivo em filmes finos (DGT, do inglês Diffusive Gradient in Thin Films) e permeação em membrana líquida (PLM, do inglês Permeation Liquid Membrane), além de técnicas cromatográficas como a cromatografia de troca iônica e o emprego de resinas complexantes (CR).

Em sua maioria, os resultados experimentais usados na modelagem NICA têm sido obtidos com eletrodos seletivos de íons (ESI), técnicas voltamétricas ou técnicas de microseparação. Os ESI têm limites de detecção muito elevados, na ordem do micromolar, que são úteis para os componentes majoritários como o cálcio, mas não são suficientes para os metais traço.

Nos últimos anos, as técnicas com maiores expectativas para a determinação da concentração do íon metálico livre são a "Donnan Membrane Technique" (DMT) e a "Absence of Gradients and Nernstian Equilibrium Stripping” (AGNES).

A técnica de DMT, que começou a ser divulgada no ano $2000,{ }^{29}$ baseia-se no transporte dos cátions metálicos por meio de uma membrana de troca catiônica interposta entre duas soluções: a amostra e uma solução receptora. A membrana de troca catiônica está inicialmente estabilizada com íons cálcio. Antes de começar o experimento, deve-se equilibrar a membrana com uma solução de íons cálcio idealmente na mesma concentração que na solução da amostra. A membrana é colocada na célula em que ocorrerá a separação entre a solução da amostra e a solução receptora, depois a solução receptora é adicionada (com a mesma concentração de cálcio em que a membrana foi equilibrada) e introduz-se a solução de amostra. A concentração de íons cálcio idealmente é a mesma nos três compartimentos (soluções amostra e receptora e na membrana), sendo que a solução da amostra contém os íons metálicos de interesse. Ao entrar em contato, os íons metálicos livres (mas não os complexados) vão começar a permear a membrana de troca catiônica e se acumular na solução receptora até que atinja o equilíbrio. Neste momento, pode-se recolher a solução receptora e medir a concentração de íons metálicos, normalmente por espectrometria de emissão óptica com plasma indutivamente acoplado (ICP OES), que será idêntica à concentração de íons metálicos livres na amostra. Esta técnica é especialmente útil para determinar concentrações de íons metálicos livres no ambiente ${ }^{30,31}$ mas, devido ao tempo de equilíbrio necessário para cada ponto é muito difícil utilizá-la na determinação de parâmetros NICA, embora seja particularmente útil, para íons difíceis de determinar usando outras técnicas como por exemplo, o alumínio. ${ }^{32}$

A AGNES é uma técnica eletroquímica de redissolução, consistindo em duas etapas sequenciais: uma etapa de deposição, em que se aplica um potencial próximo do potencial de redução padrão do metal e se espera até atingir o equilíbrio termodinâmico entre o metal amalgamado e o interior da solução, e em uma segunda etapa, reoxida-se o metal amalgamado com intuito de medi-lo. ${ }^{33}$

No fim da etapa de deposição, obtém-se a razão entre o metal amalgamado e em solução segundo a equação:

$$
Y=\frac{c_{M, \text { amalg }}}{c_{M}^{*}}=\exp \left[\frac{-n F\left(E_{1}-E^{0}\right)}{R T}\right]
$$

em que Y representa o ganho (ou fator de pré-concentração), $c_{M, a m a l g}$ é a concentração de íon metálico amalgamado, $c_{M}^{*}$ é a concentração de íon metálico no interior da solução, $E^{0}$ é o potencial de redução padrão do metal e $E_{1}$ o potencial de deposição aplicado ao eletrodo.

$\mathrm{Na}$ etapa da reoxidação o metal amalgamado é quantificado usando uma cronopotenciometria de redissolução anódica tendo $E_{1}$ como potencial inicial, ${ }^{34}$ que resulta no sinal obtido que é diretamente proporcional à concentração do íon metálico no interior da solução:

$$
\text { Sinal }=Y \cdot c_{M}^{*}
$$

AGNES funciona de uma forma análoga a um eletrodo seletivo de íons permitindo a determinação direta do valor do íon metálico livre na solução, mas com um limite de detecção muito baixo característico das técnicas eletroquímicas de redissolução anódica. Esta técnica já foi aplicada com bons resultados, por exemplo, na modelagem de chumbo $(\mathrm{Pb})$ com a matéria orgânica isolada de sistemas aquáticos urbanos, ${ }^{35}$ mas é especialmente interessante para medidas de zinco $(\mathrm{Zn})$, metal para o qual não existe um ESI comercial. ${ }^{36}$

\section{MODELAGEM NICA-DONNAN}

\section{Parametrização}

Os parâmetros NICA-Donnan apresentam regularmente uma elevada covariância, sinal de que não são completamente independentes entre si, logo, limitar o valor de um parâmetro tem consequências nos valores de outros parâmetros.

A abordagem mais utilizada consiste em tratar primeiro a interação eletrostática com a estratégia da curva mestra, ajustar a curva obtida para extrair os parâmetros NICA do hidrogênio e em seguida ajustar simultaneamente os dados experimentais disponíveis para todos os metais.

Recentemente, Lenoir et al. ${ }^{37}$ propuseram um método para garantir parâmetros mais confiáveis no seguimento de um trabalho no qual constataram que é possível obter apenas seis parâmetros independentes os quais podem ser extraídos de uma titulação potenciométrica de $\mathrm{SH} .{ }^{38}$

De fato, o elevado número de parâmetros do modelo NICADonnan não garante uma solução uniforme para um ajuste experimental, sobretudo na análise dos dados do hidrogênio. Isto aparece, por exemplo, no valor atípico baixo do $\log K_{\mathrm{H} 1}$ genérico que é de 2,34 e 2,93 respectivamente para os $\mathrm{AF}$ e $\mathrm{AH}$, muito menor que o $\mathrm{pK}_{\mathrm{a}}=$ 4,5 do ácido acético.

O método proposto ${ }^{37}$ consiste em três interações:

1) Derivar a curva carga $v s . \mathrm{pH}$ a uma dada força iônica e definir os máximos dos picos como $\log K_{\mathrm{H} 1}$ e $\log K_{\mathrm{H} 2}$. Usando estes valores, ajustar a curva a essa força iônica e obter os valores de $Q_{\operatorname{maxH1}}, Q_{\mathrm{maxH} 2}, m_{\mathrm{H} 1}$ e $m_{\mathrm{H} 2}$. Deve-se usar a equação Carga Inicial $=Q_{\operatorname{maxH} 1}+Q_{\operatorname{maxH} 2}-Q_{0}$, sendo este último um parâmetro ajustável. Este primeiro passo da interação gera valores finais de $Q_{\operatorname{maxH} 1}, Q_{\operatorname{maxH} 2}$ e $Q_{0}$.

2) Para a segunda etapa da interação, fixa-se o valor de $b$ a 0,2 , ou seja, o menor valor no intervalo possível $(0,2$ a 0,9$)$. Em seguida, ajustam-se os valores de $\log K_{\mathrm{H} 1}, \log K_{\mathrm{H} 2}, m_{\mathrm{H} 1}$ e $m_{\mathrm{H} 2}$. Como as soluções já estão condicionadas pelos valores de $Q_{\operatorname{maxH} 1}, Q_{\operatorname{maxH} 2}$ e a carga inicial, é possível que para o valor de $b$ escolhido não haja solução. Nesse caso, deve-se aumentar o valor de $b$ até obter um ajuste. Desta etapa obtém-se os valores de $m_{\mathrm{H} 1}$ e $m_{\mathrm{H} 2}$.

3) Fixando $Q_{\operatorname{maxH} 1}, Q_{\mathrm{maxH} 2}, Q_{0}, m_{\mathrm{H} 1}$ e $m_{\mathrm{H} 2}$ ajustam-se os valores de $b$, $\log K_{\mathrm{H} 1}, \log K_{\mathrm{H} 2}$. Para verificar se este é de fato o melhor ajuste fixa-se o valor de $b$ anterior e usam-se os $\log K_{\mathrm{H} 1}, \log K_{\mathrm{H} 2}$ obtidos e os valores de $m_{\mathrm{H} 1}$ e $m_{\mathrm{H} 2}$ são novamente ajustados.

Este método foi aplicado à base de dados de titulações potenciométricas do hidrogênio da qual se obtiveram os parâmetros genéricos e gerou valores de 3,54 e 3,87 para o $\log K_{\mathrm{H} 1}$, para os AF e AH, respectivamente, que são mais próximos da realidade.

\section{Programas de ajuste}

Um dos problemas atuais da modelagem NICA-Donnan é que o programa de ajuste usado para obter os parâmetros é o FIT de D. Kinniburgh, ${ }^{39}$ que é ainda um programa em sistema operacional 
MS-DOS, não podendo ser executado em sistemas operacionais de 64 bits.

Recentemente, foi publicada uma alternativa por Janot et al. ${ }^{40}$ que descreve como realizar o ajuste para obtenção dos parâmetros do modelo NICA-Donnan a partir de dados experimentais usando um acoplamento da plataforma ORCHESTRA ${ }^{5}$ (http://orchestra. meeussen.nl/) com o software de ajuste de parâmetros PEST (http:// www.pesthomepage.org/).

Esta combinação é muito versátil e os modelos podem ser facilmente implementados e modificados na plataforma ORCHESTRA. A forma de implementação encontra-se descrita em detalhe no material suplementar do artigo.

\section{A UTILIZAÇÃO DO MODELO NA ULTIMA DÉCADA}

Atualmente, ao colocar no Web Of Science uma pesquisa sobre a utilização do modelo NICA-Donnan entre 2005 e 2016 foi observado cerca de 8 mil citações. Como foi descrito na introdução, depois da publicação dos parâmetros genéricos (em 2001 para o hidrogênio ${ }^{19} \mathrm{e}$ 2003 para os cátions metálicos ${ }^{20}$ ) a ênfase tem sido na sua utilização em uma grande variedade de estudos. Para entender melhor o seu impacto, os artigos dos parâmetros genéricos têm cerca de 270 e 350 citações para o hidrogênio e para os metais, respectivamente. Assim, estes artigos têm uma influência significativa entre a comunidade que estuda as substâncias húmicas, mas a sua utilização comporta alguns riscos.

\section{Os parâmetros genéricos para o hidrogênio e íons metálicos}

Os parâmetros genéricos da acidez dos AH e AF são baseados em 49 conjuntos de dados e segundo os autores podem ser usados para modelar SH, particularmente na ausência de um conjunto de parâmetros específicos com uma incerteza de $\pm 20 \% .{ }^{19}$ Em 2003, Ritchie e Perdue ${ }^{41}$ publicaram um artigo com as titulações potenciométricas dos 14 materiais de referência da IHSS efetuadas a uma força iônica de $0,1 \mathrm{~mol} \mathrm{~L}^{-1}(\mathrm{NaCl})$, que modelaram com uma variante do modelo de Henderson-Hasselbach.

No seguimento do trabalho realizado para o hidrogênio, foram apresentados parâmetros para 23 íons metálicos (Al, Am, Ba, Ca, $\mathrm{Cd}, \mathrm{Cm}, \mathrm{Co}, \mathrm{Cr}(\mathrm{III}), \mathrm{Cu}, \mathrm{Dy}, \mathrm{Eu}, \mathrm{Fe}(\mathrm{II}), \mathrm{Fe}(\mathrm{III}), \mathrm{Hg}, \mathrm{Mg}, \mathrm{Mn}, \mathrm{Ni}$, $\mathrm{Pb}, \mathrm{Sr}, \mathrm{Th}(\mathrm{IV}), \mathrm{U}(\mathrm{VI}) \mathrm{O}(2), \mathrm{V}(\mathrm{III}) \mathrm{O}$ e Zn) com ácidos húmicos e fúlvicos. Estes foram reparametrizados a partir dos dados brutos de 171 conjuntos de dados existentes na literatura usando os parâmetros genéricos para o hidrogênio. ${ }^{20}$ Constata-se, sem surpresa, a presença dos metais tóxicos do ponto de vista ambiental (Cd, $\mathrm{Cu}, \mathrm{Hg}, \mathrm{Pb}, \mathrm{Zn})$, dos cátions majoritários $(\mathrm{Ca}, \mathrm{Mg}, \mathrm{Al}, \mathrm{Fe}, \mathrm{Mn})$ e uma abundância de terras raras e urânio devido ao interesse da comunidade da energia atômica no âmbito do armazenamento de resíduos nucleares.

Um dos aspectos mais importantes da utilização dos parâmetros genéricos é a sua inclusão nas plataformas de modelos de especiação termodinâmica, que no caso do modelo de NICA-Donnan é disponibilizado no Visual MinteQ, ${ }^{1}$ ECOSAT, ${ }^{2}$ e ORCHESTRA. ${ }^{5}$

Na utilização dos parâmetros genéricos tem-se considerado que as quantidades totais de grupos carboxílicos e fenólicos $\left(Q_{\operatorname{maxH1}}\right.$ e $\left.Q_{\operatorname{maxH} 2}\right)$ não são genéricas, e que a qualidade da modelagem melhora muito quando se introduzem estes valores para as substâncias específicas no estudo, mesmo que estes sejam estimados a partir de medidas de COT (carbono orgânico total) ou COD (carbono orgânico dissolvido) e não resultantes de determinações potenciométricas. ${ }^{42,43}$

No entanto, a aplicação destes parâmetros genéricos tem sido criticada devido ao limitado número de classes em que se consideram apenas ácidos fúlvicos e húmicos, não fazendo mesmo a separação entre material de origem terrestre e aquático. Outra crítica se refere ao próprio modelo, em que, por exemplo, a adequação do modelo de Donnan, para descrever os efeitos eletrostáticos, tem sido questionada.

Não será analisada em detalhe a utilização dos parâmetros genéricos, pois não é o objetivo desta revisão, mas é importante mencionar que o surgimento dos parâmetros genéricos prejudicou o desenvolvimento do modelo de NICA-Donnan. Isso afetou tanto do ponto de vista teórico, como no enriquecimento da base de dados experimental. Por um lado, os parâmetros genéricos foram obtidos para a formulação atual do modelo de NICA-Donnan e qualquer evolução do modelo implicaria uma nova reparametrização, o que representaria muitas semanas de trabalho. Por outro lado, a quantidade e dificuldade do trabalho experimental necessário à obtenção dos parâmetros também seria improdutivo: primeiro devido ao hidrogênio e depois pelos vários íons metálicos presentes nas amostras, seguida por um ajuste dos resultados experimentais, que não é trivial, para obtenção de novos parâmetros, o que leva a poucos grupos se aventurem a determinar parâmetros específicos dos seus materiais húmicos.

Analisar-se-á, então, o que tem sido feito na última década referente a estes aspectos, que ultrapassem a simples utilização dos parâmetros genéricos, primeiro do ponto de vista teórico, depois do ponto de vista experimental e de modelagem e, finalmente, na geração de novos dados experimentais.

\section{Efeito eletrostático: críticas ao modelo de Donnan}

A utilização do modelo de Donnan para descrever a interação eletrostática dos íons metálicos com as substâncias húmicas tem sido criticada, especialmente no caso dos ácidos fúlvicos. Note-se que originalmente o modelo de Donnan foi adotado, pois é bastante simples de implementar do ponto de vista computacional, e que foi usado para substituir o modelo de esferas rígidas ${ }^{18}$ de Poisson-Boltzman.

Ainda em 1999, Avena et al. ${ }^{44}$ concluíram que o modelo de Poisson-Boltzmann de esferas rígidas é mais correto do ponto de vista físico-químico que o modelo de Donnan, pois utiliza tamanhos de moléculas mais próximos dos obtidos nas medidas viscosimétricas. Este resultado está diretamente relacionado com o fato do raio hidrodinâmico, principalmente dos ácidos fúlvicos, mas também dos ácidos húmicos serem bastante menores que a distância de Debye $\left(\kappa^{-1}\right)$ associada a sua dupla camada elétrica. Logo, o modelo de Donnan só produz uma boa curva mestra se forem usados $V_{\mathrm{D}}$ correspondentes a esferas de raio igual à soma do raio da molécula e da distância de Debye $\left(\kappa^{-1}\right)$. No caso dos ácidos húmicos, o $V_{\mathrm{D}}$ obtido é mais próximo do tamanho real da molécula, mas a variação de $V_{\mathrm{D}}$ com a força iônica necessária para obter a curva mestra é muito maior que a variação real observada por viscosimetria.

Saito et al., em 2005, ${ }^{45}$ compararam cinco modelos eletrostáticos para obter a curva mestra de titulação potenciométrica do PAHA (ácido húmico comercial purificado): Poisson-Boltzman de esfera rígida (em duas versões usando o raio hidrodinâmico e um raio ajustável), Poisson-Boltzman de esfera permeável (usando o raio hidrodinâmico e uma distribuição de potencial), Donnan (NICA) usando o $V_{\mathrm{D}}$ segundo a eq. 3, Donnan-EV, em que o $V_{\mathrm{D}}$ é ajustado à soma do raio hidrodinâmico com a distância de Debye, e Donnan-EDL, que é uma mistura de modelo de Donnan com o modelo da dupla camada elétrica difusa. Dos modelos testados, apenas o Poisson-Boltzman de esfera rígida com raio ajustável, Donnan (NICA) e Donnan-EV conseguiram produzir uma curva mestra, porém, todas diferentes entre si. Isto significa que a discriminação entre interações eletrostáticas e intrínsecas é dependente do modelo e, portanto, arbitrária. Do ponto de vista prático, o modelo Donnan (NICA) tem a vantagem de não necessitar de uma medida independentemente do raio hidrodinâmico, ou seja, de ter menos um parâmetro. 
Em 2005, Duval et al. ${ }^{46}$ realizaram um conjunto de estudos de mobilidade eletroforética de AF, em que demonstraram que estas substâncias são coloides semi-permeáveis e com elevada densidade de carga. Neste trabalho, a mobilidade eletroforética é corretamente descrita em função da permeabilidade das moléculas usando um modelo eletrocinético rigoroso. Os modelos eletrostáticos aproximados frequentemente usados para as substâncias húmicas não são capazes de reproduzir estes resultados de mobilidade eletroforética, demonstrando que do ponto de vista físico-químico não são adequados.

Em 2007, Companys et al. ${ }^{47}$ propuseram uma nova expressão para o volume de Donnan $\left(V_{\mathrm{D}}\right)$, com apenas um parâmetro ajustável (substituindo a eq. 3) baseada na análise das soluções analíticas da equação de Poisson-Boltzman não linear (PBNL) para geometrias planas, cilíndricas e esféricas:

$$
V_{D}=\frac{1}{4 a \sqrt{I+a^{2} Q^{2} z^{2}}}
$$

em que $z$ é a carga do eletrólito de fundo, $Q$ a carga das $\mathrm{SH}$ e $a$ é um parâmetro ajustável relacionado com a área superficial. Esta equação produz resultados muito semelhantes à $\mathrm{PBNL}$, com um tratamento numérico muito mais simples. A equação proposta foi testada em titulações de $\mathrm{SH}$ e produziu resultados $V_{\mathrm{D}}$ mais próximos da realidade física que os obtidos com a equação 3.

Em 2010, Orsetti et $a l .{ }^{48}$ propuseram um novo modelo para descrever a contribuição eletrostática para a complexação de íons pelas $\mathrm{SH}$, o modelo de rede elástica de polieletrólitos (EPN). Este modelo considera a substância húmica composta por duas partes: uma parte externa, em contato com a solução e uma parte interna, que é tratada como um gel, considerada como uma rede de polímeros com carga que é preenchida pela solução de eletrólito, de acordo com a teoria de polímeros de Flory. O efeito eletrostático é conferido por um potencial do tipo de Donnan que tem um valor médio idêntico em toda a fração de gel, fazendo com que este se expanda ou contraia em função da variação do potencial com o pH e a força iônica. Este modelo foi testado com dados experimentais publicados e forneceu uma curva mestra com qualidade semelhante à obtida com o modelo NICA-Donnan, mas com parâmetros mais razoáveis, do ponto de vista físico-químico. Na sequência deste trabalho os autores propuseram o modelo NICA-EPN ${ }^{49}$ e modelaram vários conjuntos de dados existentes na literatura. Concluíram que o modelo proposto descreve bem os resultados experimentais, sendo que a contribuição eletrostática do modelo EPN é menor que a do modelo de Donnan, tendo como consequência que as constantes específicas do NICA-EPN são maiores que as reportadas para o NICA-Donnan.

Um dos aspectos interessantes é que todo o desenvolvimento das teorias eletrostáticas foi realizado com base no íon hidrogênio nas respectivas titulações de $\mathrm{pH}$, assumindo que a força iônica é controlada por eletrólitos 1:1. Recentemente, Town e Van Leeuwen colocaram esse pressuposto, aplicando uma mistura de teoria de condensação de Manning e efeito de Donnan (modelo CCD) para explicar a complexação de íons pelas $\mathrm{SH}$, primeiro com $\mathrm{Ca}(\mathrm{II})^{50} \mathrm{e}$, em seguida, estudaram a influência na complexação de $\mathrm{Cd}(\mathrm{II}) / \mathrm{Pb}(\mathrm{II}) \mathrm{e}$ $\mathrm{Cu}(\mathrm{II}) .{ }^{51}$ Dessa forma, compararam os resultados obtidos por CCD e NICA-Donnan para a complexação de $\mathrm{Cd}(\mathrm{II}) / \mathrm{Pb}$ (II) e $\mathrm{Cu}$ (II) em eletrólito 1:1 $\left(\mathrm{KNO}_{3}\right)$ e 1:2 $\left(\mathrm{Ca}\left(\mathrm{NO}_{3}\right)_{2}\right) \cdot{ }^{52}$ e a heterogeneidade intrínseca da complexação de $\mathrm{Cd}$ (II) e $\mathrm{Cu}$ (II) com AH usando o modelo CCD. ${ }^{53}$

\section{O significado da equação NICA e sua aplicação na complexação de metais pelas substâncias húmicas}

A equação NICA é uma equação aproximada, pois baseia-se em propor uma função de distribuição de constantes de afinidade, o que tem levantado algumas questões sobre o seu significado, do ponto de vista físico-químico. Preocupados com esta questão, o grupo de Puy e Galceran na Universidade de Lleida realizaram uma série muito interessante de trabalhos sobre o tema. Em primeiro lugar, propuseram o conceito de espectro de afinidades condicionais $(\mathrm{CAS})^{54}$ que é, de fato, a função de distribuição das constantes de afinidade (ou complexação) efetivas do cátion com uma das posições de ligação, mantendo-se constante as concentrações de todas as outras posições de complexação. Em uma segunda etapa determinaram o CAS subjacente à equação NICA,,$^{55,56}$ demonstrando que esta existe para qualquer conjunto de parâmetros $p$ e $n$. Mostraram ainda que o parâmetro $p$ influencia a correlação entre as energias de complexação dos íons competidores, ou seja, um valor baixo de $p$ significa que as posições de afinidade que são fortes para o hidrogênio, são também fortes para os íons metálicos. Em seguida, apresentaram o efeito de misturas de íons metálicos no CAS, permitindo a investigação do efeito da complexação de um íon sobre os outros e representaram o CAS de um AF genérico para 14 íons metálicos, incluindo os cátions traço e majoritários. O CAS permitiu distinguir três grandes grupos de cátions: (a) $\mathrm{Al}, \mathrm{H}, \mathrm{Pb}, \mathrm{Hg}$ e $\mathrm{Cr}$, preferencialmente complexados pelos grupos fenólicos; (b) $\mathrm{Ca}, \mathrm{Mg}, \mathrm{Cd}, \mathrm{Fe}(\mathrm{II})$ e $\mathrm{Mn}$, preferencialmente complexados pelos grupos carboxílicos e (c) $\mathrm{Cu}, \mathrm{Zn}$ e Ni, nos quais as distribuições se encontraram sobrepostas não tendo preferência. ${ }^{57}$ Em 2010, apresentaram um trabalho no qual estudam a influência dos íons metálicos na interação da matéria orgânica com o hidrogênio, propondo uma nova metodologia experimental que consiste em efetuar as titulações potenciométricas do hidrogênio em presença de concentração constante de um íon metálico em competição (CAScTM). Esta metodologia permitiu verificar que as constantes de acidez são influenciadas pelos íons metálicos. ${ }^{58}$

Em outro trabalho interessante sobre a aplicação da equação NICA, Orsetti et al..$^{59}$ utilizaram um procedimento padronizado para extrair a distribuição de afinidade condicional a partir das curvas de titulação para o hidrogênio e para $\mathrm{Cd}(\mathrm{II}), \mathrm{Pb}$ (II) e $\mathrm{Cu}$ (II). Neste trabalho constataram que para o hidrogênio as distribuições são, na maioria dos casos, bimodais (carboxílicos e fenólicos), como assumido na literatura. Mas em alguns casos de AF encontraram distribuições trimodais, com um pequeno pico entre as duas distribuições normalmente encontradas. Para o $\mathrm{Cd}(\mathrm{II}), \mathrm{Pb}$ (II) as distribuições são bimodais, mas para o $\mathrm{Cu}(\mathrm{II})$ encontraram situações mais complexas com três e, por vezes, quatro picos, podendo estes serem atribuídos à complexação com mais de dois ligantes. Esta observação põe em questão a distribuição bimodal que é uma das premissas fundamentais do modelo NICA.

\section{As titulações espectrofotométricas diferenciais e a extinção de fluorescência}

Diferentes técnicas espectroscópicas são usadas na caracterização das SH, mas só há pouco tempo estão sendo utilizadas para estudar a protonação das substâncias húmicas e a sua interação com os íons metálicos, devido aos trabalhos e colaboração entre os grupos de Korshin, Benedetti e Yan. ${ }^{63-70}$

Em 2008, Dryer et al. ${ }^{60}$ publicaram um estudo no qual mostraram que o espectro de absorção diferencial UV/VIS, gerado em diferentes valores de $\mathrm{pH}$ de dois ácidos fúlvicos aquáticos, Suwanee river (SRFA) e South Plate fulvic acid, estavam de acordo com a previsões da teoria NICA-Donnan. Além disso, também identificaram dois tipos de cromóforos reativos ao $\mathrm{pH}$ que reproduzem o comportamento dos grupos carboxílicos e fenólicos observados nas titulações ácido-base. Em 2010, Janot et al. ${ }^{61}$ demonstraram que as titulações espectrofotométricas diferenciais permitem obter informação sobre a protonação das $\mathrm{SH}$ em concentrações mais baixas $\left(5 \mathrm{mg} \mathrm{L}^{-1}\right)$ que 
as frequentemente usadas em potenciometria (entre $250 \mathrm{mg} \mathrm{L}^{-1} \mathrm{a}$ $2 \mathrm{~g} \mathrm{~L}^{-1}$ ), mas também demonstraram que a força iônica afeta os resultados espectrofotométricos de uma forma distinta dos resultados potenciométricos e que, por isso, é necessário determinar a função de transferência entre a variação de carga $(\Delta \mathrm{Q})$ e a variação de absorvância $(\Delta \mathrm{A})$ para cada material. $\mathrm{O}$ mesmo grupo usou esta técnica para avaliar as modificações no PAHA, após adsorção em alumina, quando se verificou que a quantidade de posições de baixa afinidade para o hidrogênio diminuía. ${ }^{62} \mathrm{Em}$ 2013, Yan et al. ${ }^{63}$ analisaram a MON do Rio Negro e duas frações purificadas (HPO, TPH) usando titulações UV/VIS diferenciais e titulações potenciométricas. As titulações UV/VIS diferenciais foram analisadas por deconvolução, com isso, mostraram a presença de seis bandas bem resolvidas que podem ser atribuídas aos grupos carboxílicos e fenólicos. A análise do declive entre 325 e $375 \mathrm{~nm}$ do espectro diferencial UV/VIS em função do pH também reproduz bem os resultados das titulações potenciométricas e a modelagem com o NICA-Donnan. Em 2016, Yan, Dryer e Korshin ${ }^{64}$ investigaram, por titulações UV/VIS diferenciais, as frações hidrofóbicas, transfilicas e hidrofílicas da MON em três pontos de duas estações de tratamento de água. A deconvolução dos espectros revelou as seis bandas observadas anteriormente, que apresentaram variações ao longo do tratamento. A variação de intensidade diferencial a $350 \mathrm{~nm}$ em função do $\mathrm{pH}$ foi usada para obter os parâmetros NICA. Os resultados apresentados neste trabalho devem ser usados com precaução, pois não há nenhuma menção sobre a força iônica em todo o texto.

Em 2013, Yan, Benedetti e Korshin ${ }^{65,66}$ introduzem o conceito de como obter dados para a interação de metais com as SH sob análise de espectros diferenciais de UV/VIS. Estudaram a interação de $\mathrm{Cu}(\mathrm{II}), \mathrm{Cd}(\mathrm{II}), \mathrm{Fe}(\mathrm{III})$ e $\mathrm{Al}(\mathrm{III})$ com o ácido fúlvico (SRFA), em função do pH, por meio de dois parâmetros: o declive entre $325 \mathrm{e}$ $375 \mathrm{~nm}$ do espectro diferencial UV/VIS (DSlope ${ }_{325-375}$ ) e o diferencial do logaritmo da absorvância a $350 \mathrm{~nm}\left(\mathrm{DlnA}_{350}\right)$. Dessa forma, mostrou-se que estes parâmetros estão fortemente relacionados com a modelização NICA-Donnan. Em 2014, Yan e Korshin ${ }^{67}$ estudaram a interação de SRFA com nove metais: $\mathrm{Ca}$ (II), $\mathrm{Mg}$ (II), $\mathrm{Fe}$ (III), $\mathrm{Al}$ (III), $\mathrm{Cu}(\mathrm{II}), \mathrm{Cd}(\mathrm{II}), \mathrm{Cr}(\mathrm{III}), \mathrm{Eu}(\mathrm{III})$, and Th(IV). A deconvolução do espectro diferencial UV/VIS produziu seis bandas com máximos em 200, 240, 276, 316, 385, e $547 \mathrm{~nm}$. Mostraram que a intensidade da banda a $316 \mathrm{~nm}$ é diretamente proporcional à concentração de metal complexado pelo SRFA.

$\mathrm{O}$ efeito da coloração na interação de $\mathrm{Al}(\mathrm{III}), \mathrm{Fe}(\mathrm{III})$ e $\mathrm{Cu}(\mathrm{II})$ com SRFA e PAHA foi estudado pelo método do espectro diferencial UV/VIS (DSlope ${ }_{325-375}$ ), cujos dados foram interpretados usando o modelo NICA-Donnan. ${ }^{68}$

A interação de Tb(III), Eu(III) e La(III) com SRHA foi estudada por extinção de fluorescência e espectroscopia diferencial UV/VIS. ${ }^{69}$ A deconvolução do espectro de absorvância diferencial mostrou a existência de sete bandas com sinais positivos e negativos, as quais variam com o pH e concentração total de íons de semelhantes para os três íons estudados. A intensidade da banda de $387 \mathrm{~nm}$ é proporcíonal à quantidade de íons complexados e correlaciona-se bem com o modelo NICA-Donnan para o caso do Eu(III). A extinção de fluorescência comportou-se como esperado para o $\mathrm{Tb}(\mathrm{III})$ e Eu(III), mas o La(III) não afetou a emissão do "Suwanee River Humic Acid" (SRHA).

Em 2015, Gao et al. ${ }^{70}$ estudaram o efeito da variação da força iônica entre 0,001 e 0,3 mol L-1 em diferentes substâncias húmicas (SRFA, SRHA e PLFA), e observaram que foi provocado um aumento de absorvância. Este aumento é maior em $\mathrm{pH}$ mais elevados, indicando uma maior desprotonação dos cromóforos com o aumento da força iônica, e correlaciona-se bem com a desprotonação dos grupos fenólicos prevista pelo modelo de NICA-Donnan.

Outra linha de pesquisa interessante tem sido a colaboração entre
Benedetti e Reiller nos estudos da interação de európio com SH, com ênfase nos estudos de espectroscopia de fluorescência resolvida no tempo (TRFLS). Em um primeiro trabalho, em 2008, ${ }^{71}$ obtiveram os parâmetros de NICA para o Eu(III) por TRFLS a partir de dados de competição com $\mathrm{Ca}$ (II) e $\mathrm{Cu}$ (II) para um ácido húmico de solos. Essa pesquisa foi continuada, em 2013, ${ }^{72}$ através do estudo e modelagem do sistema ternário Eu(III), PAHA, alumina. Em 2016, ${ }^{73}$ apresentaram a influência da concentração de matéria orgânica na complexação por meio de um estudo de interação de Eu(III) com SRFA.

Segundo vários autores, os resultados demonstram que o espectro diferencial de UV/VIS pode ser usado para estudar a natureza intrínseca da complexação entre íon metálico e a MON, sendo que esta técnica pode ser usada para obter parâmetros do modelo NICA. Em nossa opinião, as titulações espectrofotométricas diferenciais são capazes de fornecer informação adicional muito relevante, mas que neste momento ainda não está demonstrado que podem ser utilizadas isoladamente para modelar a interação de íons com as SH. Isso se deve à dificuldade em quantificar o efeito da força iônica sobre os espectros.

\section{Novos parâmetros publicados a partir de 2005}

As Tabelas 1 e 2 reportam os conjuntos de novas parametrizações do modelo NICA-Donnan de hidrogênio e íons metálicos. Estas tabelas fornecem uma perspectiva geral da modelagem NICA ou NICA-Donnan efetuada na última década, mas não se refere a outros trabalhos de modelização que usam parâmetros genéricos ou plataformas de modelos como o Visual MinteQ. Se um trabalho apresenta a modelagem para o hidrogênio e outros metais, aparecerá nas duas tabelas. Mas normalmente será discutido na seção correspondente aos metais.

\section{Hidrogênio}

Florencio Arce esteve muito ativo nesta década, quando realizou vários trabalhos sobre solos utilizando o modelo NICA-Donnan para AH e AF extraídos de turfa ombrotrófica. ${ }^{74}$ Foi feita a titulação direta de duas amostras de turfas após lavagem ácida sem purificar a matéria orgânica, usando o método da titulação de retorno de Hendershot, ${ }^{75}$ com o intuito de verificar a aplicação dos parâmetros genéricos a solos, ${ }^{28}$ a titulação de uma amostra de turfa com e sem lavagem acida $^{76}$ e um estudo de uma turfa e da humina, do AH e AF extraídos a partir dela. ${ }^{77}$ Neste último trabalho verificou-se que na turfa existe, praticamente, a mesma quantidade de grupos fenólicos que no AH purificado, mas apenas 30\% dos grupos carboxílicos, e que as constantes de acidez de ambos são semelhantes no solo e no $\mathrm{AH}$.

Uma das áreas de investigação ativas tem sido o estudo de SH extraídas de lama de esgoto ou produtos de compostagem. Frequentemente, nestes trabalhos o objetivo é avaliar o efeito do tratamento dos solos com estes materiais por meio de comparação das propriedades das substâncias húmicas extraídas dos solos tratados e não-tratados. Muitos desses trabalhos não são aqui referidos por não terem dados suficientes para realizar a modelização NICA-Donnan.

Entre outras pesquisas, Plaza et al. ${ }^{78}$ desenvolveram um interessante trabalho de comparação dos parâmetros do hidrogênio obtidos para ácidos húmicos extraídos de lama de esgoto e composto de resíduos sólidos urbanos com os ácidos húmicos extraídos de dois solos e posteriormente com os ácidos húmicos extraídos dos solos tratados com estes materiais. No seguimento deste trabalho, o mesmo grupo publicou um estudo ${ }^{79}$ sobre tratamento de solos com lamas de esgoto, com e sem tratamento térmico, em que foram comparados os ácidos húmicos e fúlvicos extraídos do solo, com e sem tratamento, com as substâncias húmicas purificadas a partir das lamas de esgoto. Os AH e AF dos solos tratados especialmente com as lamas com tratamento 
térmico apresentaram um menor conteúdo de grupos ácidos e maior afinidade para o hidrogênio, para os grupos carboxílicos e fenólicos.

Em 2009, Van Zomeren et al. ${ }^{80}$ determinaram os parâmetros de protonação de AF extraídos de lama de esgoto, duas amostras de matéria orgânica dissolvida (MOD) natural e três amostras de cinzas industriais, onde se constatou que os parâmetros de protonação NICA-Donnan do AF de MON e de origem industrial e antropogênica são semelhantes.

Drosos et al. ${ }^{81}$ fracionaram um AH de solo e outro AH de lignita com um método de fracionamento em três etapas: uma primeira etapa de extração com HF (ácido fluorídrico), seguida por uma lavagem com citrato em $\mathrm{pH}$ 10, e finalmente a passagem por uma resina XAD 8 com recuperação do permeado a diferentes $\mathrm{pH}$. A titulação das frações revelou um aumento dos carboxílicos para o $\mathrm{AH}$ derivado da lignita comparado com o material de origem.

Em 2010, Maurer et al. ${ }^{82}$ estudaram o efeito de uma redução eletroquímica sobre AH extraídos de solo, comparando os parâmetros NICA para o hidrogênio dos AH não tratados e sua forma reduzida, observando que houve um aumento de $15 \%$ de grupos ácidos após o tratamento.

O modelo NICA-Donnan tem sido aplicado a outros materiais heterogêneos, dentre os quais podemos citar os trabalhos de Lamelas et al..$^{83} \mathrm{com}$ polissacarídeos extraídos de bactérias (EPS), Zhao et $a l .,{ }^{84}$ com de pó de bambu, e Ederer et al. ${ }^{85}$ com diferentes óxidos de grafeno.

\section{Íons metálicos}

Em paralelo com o trabalho efetuado para o hidrogênio, o grupo de Santiago de Compostela também realizou vários trabalhos com íons metálicos, começando com o estudo da complexação de $\mathrm{Cu}$ (II) com AH e AF extraídos de dois horizontes de turfa ombrotrófica, ${ }^{94}$ quando constataram que o AH complexa mais que o FA e que não existe uma diferença significativa entre os dois horizontes. Em seguida, estudaram a complexação de $\mathrm{Cd}$ (II), $\mathrm{Cu}$ (II) e $\mathrm{Pb}$ (II) com o horizonte superior da mesma turfa ${ }^{95}$ e observaram que o AH complexa os três metais mais fortemente que o AF e que a força de complexação segue a ordem $\mathrm{Cu}>\mathrm{Pb}>\mathrm{Cd}$. Estudaram também a diferença entre a complexação de $\mathrm{Cd}(\mathrm{II}), \mathrm{Cu}$ (II) e $\mathrm{Pb}$ (II) com uma suspensão de solo obtida de uma turfa e o AH extraído dela, ${ }^{96}$ quando se observou que as curvas de complexação do cátion-solo e cátion-AH são praticamente paralelas, embora mais íons metálicos sejam absorvidos por $\mathrm{Kg}$ de $\mathrm{AH}$ do que na turfa e que o efeito do $\mathrm{pH}$ é semelhante na turfa e AH purificado.

Em 2005, Ge e Hendershot ${ }^{97}$ estudaram a interação de Cd(II), $\mathrm{Hg}$ (II), $\mathrm{Pb}$ (II) em 31 solos de diferentes características por meio de um método de batelada a pH 6 e $0,01 \mathrm{~mol} \mathrm{~L}^{-1}$ de força iônica. Em seguida modelaram os parâmetros de NICA para os grupos carboxílicos, usando os parâmetros do hidrogênio que tinham determinado anteriormente para os mesmos solos. ${ }^{75}$ Os resultados mostraram que a complexação é fortemente afetada pela quantidade de matéria orgânica presente no solo; que os solos em geral tinham maior afinidade

Tabela 1. Modelagem para o hidrogênio desde 2005

\begin{tabular}{|c|c|c|c|}
\hline Tipo de material & $\Delta \mathrm{pH}$ & $\mathrm{I} / \mathrm{M}$ & Referência \\
\hline AH e AF de dois horizontes de turfa ombrotrófica & $3,5-10,0$ & $0,005-0,10-0,1$ & Gondar et al. ${ }^{74}$ \\
\hline Uma turfa com e sem lavagem ácida & $3,5-10,5$ & $0,01-0,03-0,05-0,1-0,3$ & Lopez et $a l .{ }^{76}$ \\
\hline Turfa e seus extratos humina, $\mathrm{AH}$ dissolvidos e $\mathrm{AH}$ em suspensão & $3,5-10,5$ & $0,01-0,03-0,1-0,3$ & Lopez et al. ${ }^{77}$ \\
\hline $\begin{array}{l}\text { AH de lama de esgoto e composto de resíduos sólidos urbanos e dois solos virgens } \\
\text { tratados com estes materiais }\end{array}$ & $3,5-10,5$ & $0,01-0,05-0,1-0,3$ & Plaza et al. ${ }^{78}$ \\
\hline $\begin{array}{l}\text { AH e AF de lama de esgoto com e sem tratamento térmico e um solo virgem tratado } \\
\text { com estes materiais }\end{array}$ & $3,5-10,5$ & $0,01-0,05-0,1-0,3$ & Fernandez et al. ${ }^{79}$ \\
\hline $\begin{array}{l}\text { AF extraídos de composto, lama de esgoto, } 2 \text { amostras de DOM natural e } 3 \text { amostras } \\
\text { de cinzas industriais }\end{array}$ & $3,5-10,5$ & $0,01-0,03-0,1-0,3$ & Van Zomeren et al. ${ }^{80}$ \\
\hline $\mathrm{AH}$ e $\mathrm{AH}(\mathrm{L})$ fracionados & $3,0-10,0$ & $0,001 *$ & Drosos et al. ${ }^{81}$ \\
\hline AH de solo não tratada e reduzida & $3,5-10,5$ & $0,01-0,03-0,1-0,3$ & Maurer et al. ${ }^{82}$ \\
\hline EPS de R. meliloti & $3,0-10,0$ & $0,01-0,05-0,1$ & Lamelas et al..$^{83}$ \\
\hline Pó de bambu & $3,5-10,5$ & $0,01-0,10-1,0$ & Zhao et al. ${ }^{84}$ \\
\hline Diferentes óxidos de grafeno & $3,0-11,0$ & Não indicado* & Ederer et $a{ }^{85}$ \\
\hline AH e AF extraído de DOM de águas subterrâneas profundas & $3,0-10,0$ & $0,006-0,01-0,1$ & Saito et al. ${ }^{86}$ \\
\hline $\begin{array}{l}\text { AH de lama de esgoto e composto de resíduos sólidos urbanos e dois solos um arenoso } \\
\text { e outro argiloso }\end{array}$ & $3,5-10,5$ & $0,01-0,05-0,1-0,3$ & Pedra et al. ${ }^{87}$ \\
\hline $\begin{array}{l}\text { AF de um solo virgem tratado com dois compostos (de palha e coníferas) e das amostras } \\
\text { peneiradas }<20 \mu \mathrm{m}\end{array}$ & $3,5-10,5$ & $0,1 *$ & Sebastia et al..$^{88}$ \\
\hline $1 \mathrm{AF}$ e $2 \mathrm{AH}$ de solo e $\mathrm{AH}$ de lignita & $3,5-10,5$ & $0,01-0,05-0,2$ & Tan et al. ${ }^{89}$ \\
\hline PPHA (IHSS), AH de solo & $3,5-10,0$ & $0,01 *$ & Vidali et al. ${ }^{90}$ \\
\hline Duas turfas (com lavagem ácida) & $3,0-10,0$ & $0,01-0,05-0,2$ & Vasiliadis et al. ${ }^{91}$ \\
\hline AH comercial purificado (PAHA) & $3,5-9,0$ & $0,002-0,01-0,05$ & Companys et $a l .{ }^{47}$ \\
\hline AH, AF, matéria transfilica e hidrofilica extraída a partir de DOM do Rio Sena & $3,5-10,5$ & $0,05-0,1$ & Pernet-Coudrier et al. ${ }^{35}$ \\
\hline MON do Rio Negro, e duas frações purificadas (HPO, TPH) & $3,5-10,5$ & $0,04 *$ & Yan et al. ${ }^{63}$ \\
\hline HA precipitado (IHA) & $3,5-10,5$ & $0,1^{*}$ & Weber et $a l .{ }^{92}$ \\
\hline AF e duas frações hidrofílicas extraídas de uma solução de solo & $3,5-9,0$ & $0,003-0,1$ & van Schaik et al. ${ }^{93}$ \\
\hline
\end{tabular}

*Apenas o modelo NICA foi aplicado. 
para o $\mathrm{Pb}$ e $\mathrm{Hg}$ que para o $\mathrm{Cd}$; e que o $\mathrm{Pb}$ se liga mais aos grupos carboxílicos enquanto o $\mathrm{Hg}$ se liga mais aos grupos fenólicos.

Weng et al. ${ }^{98}$ publicaram a modelagem de $\mathrm{Cu}$ (II) com um AF extraído de solo no âmbito de um estudo de misturas ternárias metal/ AF/goetita.

Koopal nos seus trabalhos de colaboração com a China publicou vários trabalhos sobre caracterização da protonação de um AF (JGFA) e dois AH (JGHA, JLHA) de solo e AH de lignita (PAHA), ${ }^{89}$ seguido do estudo e modelagem destes com $\mathrm{Pb}(\mathrm{II})^{99}$ e $\mathrm{Cu}$ (II). ${ }^{100}$

Em 2006, Weber et al..$^{92}$ após precipitação de AH comercial da Aldrich em presença de $\mathrm{Ca}$ (II), aplicou um tratamento térmico e estudou sua protonação e interação com $\mathrm{Fe}(\mathrm{III})$ entre pH 2 e 5,5. A partir dos resultados, verificou que o potencial redox da solução é controlado pelo IHA (HA precipitado) e que, acima de pH 5,5, a especiação do $\mathrm{Fe}(\mathrm{III})$ é controlada pela formação de um precipitado amorfo com uma solubilidade superior à da ferrohidrita.

Christl et al. ${ }^{101}$ estudaram a influência da concentração de AH e AF extraídos de um solo (no intervalo de 1 a $1000 \mathrm{mg} \mathrm{L}^{-1}$ ) nos parâmetros NICA da complexação de $\mathrm{Cu}$ (II) e $\mathrm{Pb}(\mathrm{II})$. Neste trabalho obtiveram os parâmetros NICA-Donnan para concentrações elevadas de $\mathrm{AF}$ e $\mathrm{AH}$ e compararam com bons resultados da modelagem dos resultados de medidas experimentais com concentrações de $\mathrm{AF}$ e AH muito inferiores, tendo concluído que os parâmetros NICA-Donnan são independentes da concentração de $\mathrm{AF}$ ou $\mathrm{AH}$.

Vidali et al. também estudaram a influência da concentração de $\mathrm{AH}$ (de 20 a $200 \mathrm{mg} \mathrm{L}^{-1}$ ) nos parâmetros NICA-Donnan para o hidrogênio ${ }^{90} \mathrm{e} \mathrm{Cu}(\mathrm{II})^{102}$ com um AH de referência da IHSS (PPHA) e um AH extraído de um solo grego. Ao contrário do trabalho anterior, verificou-se que a complexação do $\mathrm{H}^{+}$e do $\mathrm{Cu}$ (II) dependem da concentração do $\mathrm{AH}$, por isso, foram determinados dois conjuntos de parâmetros NICA, uma para concentrações de AH superiores a $100 \mathrm{mg} \mathrm{L}^{-1} \mathrm{e}$ outra para $20 \mathrm{mg} \mathrm{L}^{-1}$.

Em 2012, Christl ${ }^{103}$ investigou a complexação de $\mathrm{Ca}$ (II) com dois $\mathrm{AH}$ de solos especialmente e a sua dependência do $\mathrm{pH}$ e da força iônica, constatando que a componente eletrostática domina a complexação deste íon.

Maurer et al. ${ }^{104}$ continuaram os estudos do efeito de uma redução eletroquímica sobre um AH extraído de solo, agora sobre a complexação de Cd(II), verificando que o aumento da complexação deste com a forma reduzida estava de acordo com o aumento da quantidade de grupos ácidos observada anteriormente. ${ }^{82}$ Expuseram, ainda, que, em relação interação com $\mathrm{Ag}(\mathrm{I})$, a forma reduzida do $\mathrm{AH}$ era capaz de reduzir a $\operatorname{Ag}(\mathrm{I})$ a $\operatorname{Ag}(0)$ formando nanopartículas de prata.

Van Schaik et al..$^{93}$ estudaram a protonação e a complexação do $\mathrm{Cu}$ (II) com o AF e duas frações hidrofílicas extraídas (TiA, HiC) de uma solução de solo. Observaram que as frações hidrofílicas contêm mais grupos ácidos que a fração hidrofóbica e que os parâmetros genéricos para o hidrogênio não dão bons resultados para estas frações, tendo sido obtidos parâmetros NICA novos para elas. A complexação de $\mathrm{Cu}$ (II) foi muito semelhante para as três frações apesar das diferenças observadas para o hidrogênio.

Pernet-Coudrier et al. ${ }^{35}$ efetuaram um estudo de protonação e

Tabela 2. Dados de modelagem desde 2005 para os íons metálicos

\begin{tabular}{|c|c|c|c|c|}
\hline Metal & Tipo de material & $\mathrm{pH}$ & $\mathrm{I} / \mathrm{M}$ & Referência \\
\hline $\mathrm{Cu}(\mathrm{II})$ & AH e AF de dois horizontes de turfa ombrotrófica & 4,$5 ; 5 ; 5,5 ; 6$ & 0,1 & Gondar et al. ${ }^{94}$ \\
\hline $\mathrm{Cd}(\mathrm{II}), \mathrm{Cu}(\mathrm{II}), \mathrm{Pb}(\mathrm{II})$ & $\begin{array}{l}\text { AH e AF do horizonte } \\
(0-60 \mathrm{~cm}) \text { de turfa ombrotrófica }\end{array}$ & 5,$5 ; 6$ & 0,1 & Gondar et al. ${ }^{95}$ \\
\hline $\mathrm{Cd}(\mathrm{II}), \mathrm{Cu}(\mathrm{II}), \mathrm{Pb}(\mathrm{II})$ & Turfa e o seu extrato AH & $4 ; 5 ; 6$ & 0,1 & Villaverde et al..$^{96}$ \\
\hline $\mathrm{Cd}(\mathrm{II}), \mathrm{Hg}(\mathrm{II}), \mathrm{Pb}(\mathrm{II})$ & 31 solos & 6 & 0,01 & Ge e Hendershot ${ }^{97}$ \\
\hline $\mathrm{Cu}(\mathrm{II})$ & AF de solo & $4 ; 6 ; 8$ & 0,1 & Weng et al..$^{98}$ \\
\hline $\mathrm{Pb}(\mathrm{II})$ & $1 \mathrm{AF}$ e $2 \mathrm{AH}$ de solo e $\mathrm{AH}$ de lignite & $4 ; 6 ; 7$ & 0,$005 ; 0,1$ & Xíong et al..$^{99}$ \\
\hline $\mathrm{Cu}(\mathrm{II})$ & $1 \mathrm{AF}$ e $2 \mathrm{AH}$ de solo e $\mathrm{AH}$ de lignite & $4 ; 5 ; 6$ & 0,$01 ; 0,1$ & $\mathrm{Xu}$ et al. ${ }^{100}$ \\
\hline $\mathrm{Cu}(\mathrm{II}), \mathrm{Pb}(\mathrm{II})$ & $\mathrm{AF}$ e AH de solo & $\begin{array}{c}\mathrm{Cu}(6,8) \\
\mathrm{Pb}(4 ; 5,5)\end{array}$ & 0,1 & Christl et al..$^{101}$ \\
\hline $\mathrm{Cu}(\mathrm{II})$ & PPHA (IHSS), AH de solo & $4 ; 6 ; 8$ & 0,$01 ; 0,1$ & Vidali et al. ${ }^{102}$ \\
\hline $\mathrm{Ca}(\mathrm{II})$ & Dois AH de solo & 4 a 8 & 0,$01 ; 0,1$ & Christl ${ }^{103}$ \\
\hline $\mathrm{Cd}(\mathrm{II})$ & AH de solo reduzida e reoxidada & $7 ; 9$ & 0,1 & Maurer et al..$^{104}$ \\
\hline $\mathrm{Cu}(\mathrm{II})$ & AF e duas frações hidrofílicas extraídas de uma solução de solo & $4 ; 6 ; 9$ & 0,03 & van Schaik et al. ${ }^{93}$ \\
\hline $\mathrm{Pb}(\mathrm{II})$ & $\begin{array}{c}\mathrm{AH}, \mathrm{AF} \text {, matéria transfilica e hidrofilica extraída a partir de DOM do } \\
\text { Rio Sena }\end{array}$ & 4 a 9 & 0,1 & Pernet-Coudrier et al. ${ }^{35}$ \\
\hline $\mathrm{Fe}(\mathrm{III})$ & HA precipitado (IHA) & 2 a 5,5 & 0,1 & Weber et al. ${ }^{92}$ \\
\hline $\mathrm{Pb}(\mathrm{II})$ & PAHA & $4 ; 5 ; 6 ; 7 ; 8 ; 9$ & 0,1 & Puy et al. 85 \\
\hline $\mathrm{Cu}(\mathrm{II})$ & AH e AF extraído de DOM de águas subterrâneas profundas & $4 ; 6 ; 8$ & 0,$01 ; 0,1$ & Saito et al. ${ }^{86}$ \\
\hline $\mathrm{Fe}(\mathrm{III})$ & MON do oceano & 7 a 8 & 0,7 & Hiemstra e Van Riemsdijk ${ }^{105}$ \\
\hline $\mathrm{Fe}(\mathrm{III}), \mathrm{Cu}(\mathrm{II})$ & MON do oceano & 8,3 até 6,8 & & Gledhill et al..$^{106}$ \\
\hline $\mathrm{Ca}(\mathrm{II}), \mathrm{Cu}(\mathrm{II}), \mathrm{Eu}(\mathrm{III})$ & AH extraído de solo & 5,5 & 0,001 & Marang et al. ${ }^{71}$ \\
\hline $\mathrm{Eu}(\mathrm{III})$ & PAHA & 4 & 0,10 & Janot et al. ${ }^{72}$ \\
\hline $\mathrm{Eu}(\mathrm{III})$ & SRFA & $4 ; 6 ; 7$ & 0,$02 ; 0,1 ; 0,5$ & Kouhail et al. ${ }^{73}$ \\
\hline $\mathrm{Cd}(\mathrm{II})$ & EPS de R. meliloti & $5 ; 7$ & 0,1 & Lamelas et al. ${ }^{83}$ \\
\hline $\mathrm{Cu}(\mathrm{II})$ & Pó de bambu & 6 a 8 & 0,$01 ; 0,1$ & Zhao et al. ${ }^{84}$ \\
\hline
\end{tabular}


complexação com $\mathrm{Pb}$ (II) com $\mathrm{AH}, \mathrm{AF}$, matéria transfilica e hidrofílica extraída de MON do Rio Sena. Concluíram que a fração mais hidrofílica tem a maior quantidade de carga e maior capacidade de complexação para o $\mathrm{Pb}(\mathrm{II})$ (49\% do $\mathrm{Pb}$ complexado a pH 7), o que ilustra a importância de contabilizar os compostos mais hidrofílicos na especiação global dos íons metálicos.

Em 2015, Saito et al. ${ }^{86}$ apresentaram um interessante estudo sobre AH e AF extraídos de águas subterrâneas profundas no qual modelizaram a protonação e a interação com o $\mathrm{Cu}$ (II). Foi observado que a complexação do $\mathrm{Cu}$ (II) com este material é mais fraca que com os materiais extraídos de MOD de águas superficiais.

Em 2006, Hiemstra e Van Riemsdijk ${ }^{105}$ apresentaram um trabalho interessante de modelagem utilizando NICA-Donnan para o Fe(III) com a MON do oceano e precipitação de oxo/hidróxidos de Ferro baseado em uma série de dados experimentais publicados em diferentes trabalhos. Em 2015, Gledhill et al. ${ }^{106}$ estudaram a influência da acidificação do oceano, variando o $\mathrm{pH}$ de 8,3 até 6,8 na especiação de $\mathrm{Fe}(\mathrm{III})$ e $\mathrm{Cu}$ (II) ajustando os parâmetros o modelo NICA-Donnan com os dados experimentais obtidos.

Marang et al. ${ }^{71}$ apresentaram a modelização de $\mathrm{Ca}(\mathrm{II})$ e $\mathrm{Cu}(\mathrm{II})$ com um AH extraído de solo a partir de dados obtidos com ESI e obtiveram por competição os parâmetros NICA para o Eu(III). O mesmo grupo apresentou ainda parâmetros NICA para o Eu(III) usando TRLFS com PAHA ${ }^{72}$ e SRFA. ${ }^{73}$

Os modelos de NICA-Donnan também têm sido usados para estudar a complexação de metais com outros complexantes orgânicos heterogêneos. Por exemplo, em 2006, Lamelas et al. ${ }^{83}$ modelaram a protonação de polissacarídeos extraídos da bactéria $R$. Meliloti e a sua interação com o Cd(II), observando que os EPS podem ter um papel importante na complexação de $\mathrm{Cd}(\mathrm{II})$ no ambiente.

Zhao et al. ${ }^{84}$ apresentaram parâmetros NICA para a complexação de $\mathrm{Cu}(\mathrm{II})$ com pó de bambu, observando que, na maior parte das condições, formavam-se complexos monodentados, exceto à baixa força iônica e $\mathrm{pH}$ elevado quando se observa a formação de complexos bidentados.

\section{CONCLUSÃO}

Esta revisão mostra que na última década o modelo de NICADonnnan tem sido muito utilizado em plataformas de modelos como o VMinteq, baseadas em parâmetros genéricos, mas esse modelo tem evoluído pouco do ponto de vista teórico e da produção de novos parâmetros experimentais para diferentes metais ou diferentes materiais, em parte decorrente da dificuldade em modelizar os dados com programas que estão desatualizados.

Do ponto de vista teórico, a equação NICA-Donnan encontra-se bem estudada. Do ponto de vista químico-físico é urgente reavaliar o modelo de Donnan, ou pelo menos a forma como o $V_{\mathrm{D}}$ é calculado, especialmente no caso dos AF e nas situações em que a força iônica do meio possa ser definida por cátions divalentes (Ca(II) ou $\mathrm{Mg}(\mathrm{II})$ ).

A integração do modelo NICA-Donnan em plataformas de modelos de especiação é uma realidade e também um dos maiores desafios, uma vez que a complexação de metais em sistemas multissuperfície é um problema complicado devido à possibilidade dessas superfícies interagirem entre si, como no caso da adsorção da MON na superfície das partículas de óxo/hidróxidos de ferro. $\mathrm{O}$ estudo e modelagem de sistemas ternários metal/MON/partículas e quaternários metal/MON/partículas/organismos é um dos maiores desafios dos próximos anos.

Dentre este desafio é interessante verificar que a maior quantidade de trabalho efetuado continua a ser sobre solos, quer diretamente ou da matéria orgânica proveniente deles. Do nosso ponto de vista, existem ainda muitas questões em aberto sobre a natureza e organização da matéria orgânica nos solos e o efeito dos diferentes processos de extração, embora se reconheça a importância da padronização dos experimentos para comparação dos resultados obtidos de amostras de diferentes amostras e regiões. É, pois, necessário diferenciar o modelo NICA-Donnan, ou pelo menos os parâmetros genéricos em pedogênicos e aquagênicos, e compreender as mudanças provocadas pelas extrações, bem como compreender o efeito dos outros componentes do solo na complexação dos metais e na organização estrutural da matéria orgânica no solo.

Outro aspecto relevante é a possível contribuição de compostos orgânicos mais hidrofílicos para a complexação dos metais, o que ilustra a necessidade de aumentar a variedade de parâmetros genéricos, de preferência após uma divisão mais cuidadosa da MON em várias classes, de acordo com critérios bem definidos, por exemplo de marcadores moleculares.

O conjunto de desafios apresentados, bem como a disponibilização da ferramenta ORCHESTRA-PEST para modelar novos dados experimentais em múltiplas superfícies de complexação e modificar facilmente o modelo subjacente, abrem novas possibilidades de evolução tanto teórica como de modelização de resultados para a próxima década.

\section{MATERIAL SUPLEMENTAR}

Material suplementar está disponível em http://quimicanova.sbq. org.br, na forma de arquivo PDF, com acesso livre.

\section{AGRADECIMENTOS}

Os autores reconhecem o suporte da FAPESP (Proc. 2016/082154) e do CNPq (Proc. 303189/2013-4, 445189/2014-2), bem como das agências nacionais francesa e portuguesa ANR e FCT no projeto bilateral ANR Species (FCT-ANR/AAG-MAA/0065/2012 and Blanc International II - SIMI 6 - Système Terre Environnement Risques SPECIES). A.S.C. Monteiro agradece a bolsa de doutorado da FAPESP (Proc. 2013/14122-0) e A.H. Rosa/J.P. Pinheiro uma bolsa de pesquisador visitante especial do CNPq/Brasil (PVE 400572/2013-3).

\section{REFERÊNCIAS}

1. Gustafsson, J. P.; Visual MINTEQ ver. 3.1; KTH Royal Institute of Technology, Sweden, 2016.

2. Keizer, M. G.; van Riemsdijk, W. H.; ECOSAT: a computer program for the calculation of chemical speciation and transport in soil-water systems, Universidade de Wagening, Holanda, 1995.

3. Parkhurst, D. L.; Appelo, C. A. J.; Description of Input and Examples for PHREEQC Version 3; A Computer Program for Speciation, BatchReaction, One-Dimensional Transport, and Inverse Geochemical Calculations. U.S. Geological Survey Techniques and Methods, book 6, 2013, cap. 6.

4. Tipping, E. W.; Comput. Geosci. 1994, 20, 973.

5. Meeussen, J. C. L.; Environ. Sci. Technol. 2003, 15, 1175.

6. Buffle, J.; Complexation reactions in aquatic systems: An analytical approach,: Ellis Horwood: Chichester, 1988.

7. Stevenson, F. J.; Humus Chemistry: Genesis, Compositíon, Reactions, John Wiley \& Sons, 1994.

8. Tan, K. H.; Humic Matter in Soil and the Environment: Principles and Controversies, $2^{\text {nd }}$ ed., CRC Press, 2014.

9. Lehmann, J.; Kleber, M.; Nature 2015, 528, 60.

10. Maccarthy, P.; Geoderma 1976, 16, 179.

11. Abbt-Braun, G.; Thirty years of IHSS, IHSS Newsletter - Polish Chapter of the IHSS, Wroclaw, Poland, 2012.

12. http:/www.humic-substances.org/, acessada em julho 2017. 
13. Tipping, E.; Hurley, M.; Geochim. Cosmochim. Acta. 1992, 56, 3627.

14. Tipping, E.; Aquat. Geochem. 1998, 4, 3.

15. Tipping, E.; Lofts, S.; Sonke, J. E.; Environ. Chem. 2011, 8, 225.

16. Dewit, J.; Van Riemsdijk, W. H; Koopal, L. K.; Environ. Sci. Technol. 1993, 27, 2015

17. Benedetti, M.; Milne, C.; Kinniburgh, D.; Van Riemsdijk, W.; Koopal, L. K; Environ. Sci. Technol. 1995, 29, 446.

18. Benedetti, M. F.; Van Riemsdik, W. H.; Koopal, L. K.; Environ. Sci. Technol. 1996, 30, 1805.

19. Milne, C. J.; Kinniburgh, D. G.; Tipping, E.; Environ. Sci. Technol. 2001, 35, 2049.

20. Milne, C. J.; Kinniburgh, D. G.; Van Riemsdijk, W. H.; Tipping, E.; Environ. Sci. Technol. 2003, 37, 958.

21. Koopal, L. K.; Saito, T.; Pinheiro, J. P.; Van Riemsdijk, W. H.; Colloids Surf., A 2005, 65, 40.

22. Dewit, J.; Van Riemsdijk, W. H.; Koopal, L. K.; Environ. Sci. Technol. 1993, 27, 2005.

23. Kinniburgh, D. G.; Milne, C. J.; Benedetti, M. F.; Pinheiro, J. P.; Filius, J.; Koopal, L. K.; Environ. Sci Technol. 1996, 30, 1687.

24. Jaroniec, M.; Adv. Colloid Interface Sci. 1983, 18, 149.

25. Baker, C. T. H.; The Numerical Treatment of Integral Equations, $1^{\text {st }}$ ed.,: Clarendon Press: Oxford, 1977.

26. Nederlof, M.; Dewit, J.; Van Riemsdijk, W. H; Koopal, L. K.; Environ. Sci. Technol. 1993, 27, 846.

27. Ritchie, J. D.; Perdue, E. M.; Org. Geochem. 2008, 39, 783.

28. Pesavento, M.; Alberti, G.; Biesuz, R.; Anal. Chim. Acta. 2009, 631, 129.

29. Temminghoff, E. J. M.; Plette, A. C. C.; Van, E. R.; Van Riemsdijk, W. H.; Anal. Chim. Acta. 2000, 417, 149.

30. Sigg, L.; Black, F.; Buffle, J.; Cao, J.; Cleven, R.; Davison, W.; Environ. Sci. Technol. 2006, 40, 1934.

31. Kalis, E. J. J.; Weng, L. P. Dousma, F.; Temminghoff, E. J. M.; Van Riemsdijk, W. H.; Environ. Sci. Technol. 2006, 40, 955.

32. Weng, L. P.; Temminghoff, E. J. M.; Van Riemsdijk, W. H.; Environ. Sci.: Water Res. Technol. 2002, 36, 4215.

33. Galceran, J.; Companys, E.; Puy, J.; Cecilia, J.; Garces, J. L.; J. Electroanal. Chem. 2004, 566, 95.

34. Parat, C.; Authier, L.; Aguilar, D.; Companys, E.; Puy, J.; Galceran, J.; Analyst 2011, 136, 4337

35. Pernet-Coudrier, B.; Companys, E.; Galceran, J.; Morey, M.; Mouchel, J. M.; Puy, J.; Geochim. Cosmochim. Acta. 2011, 75, 4005.

36. Chito, D.; Weng, L.; Galceran, J.; Companys, E.; Puy, J.; Van Riemsdijk, W. H.; Sci. Total Environ. 2012, 421, 238.

37. Lenoir, T.; Matynia, A.; Manceau, A.; Environ. Sci. Technol. 2010, 44, 6221.

38. Lenoir, T.; Manceau, A.; Langmuir 2010, 26, 3998.

39. Kinniburgh, D. G.; FIT User Guide, Technical Report WD/93/23. British Geological Survey 1993 (Keyworth: UK).

40. Janot, N.; Pinheiro, J. P.; Botero, W. G.; Meeussen, J. C. L.; Groenenberg, J. E.; Environ. Chem. 2016, 14, 38.

41. Ritchie, J. D.; Perdue, E. M.; Geochim. Cosmochim. Acta. 2003, 67, 85.

42. Ponthieu, M.; Pourret, O.; Marin, B.; Schneider, A. R.; Morvan, X.; Conreux, A.; J. Geochem. Explor. 2016, 165,1.

43. Ren, Z. L.; Tella, M.; Bravin, M. N.; Comans, R. N. J.; Dai, J.; Garnier, J. M.; Chem. Geol. 2015, 398, 61.

44. Avena, M. J.; Koopal, L. K.; Van Riemsdijk, W. H.; J. Colloid. Interface Sci. 1999, 217, 37.

45. Saito, T.; Nagasaki, S.; Tanaka, S.; Koopal, L. K.; Colloids Surf., A 2005, 265, 104.

46. Duval, J. F. L.; Wilkinson, K. J.; Van Leeuwen, H. P.; Buffle, J.; Environ. Sci. Technol. 2005, 39, 6435.

47. Companys, E.; Garces, J. L.; Salvador, J.; Galceran, J.; Puy, J.; Mas, F.; Colloids Surf., A 2007, 306, 2.

48. Orsetti, S.; Andrade, E. M.; Molina, F. V.; Langmuir 2010, 26, 3134.
49. Montenegro, A. C.; Orsetti, S.; Molina, F. V.; Environ. Chem. 2014, 11, 318.

50. Van Leeuwen, H. P.; Town, R. M.; Environ. Chem. 2016, 13,76.

51. Town, R. M.; Van Leeuwen, H. P.; Chem Phys. 2016, 18, 10049

52. Town, R.M.; Van Leeuwen, H. P.; J. Phys. Chem. 2016, $18,18024$.

53. Town, R. M.; Van Leeuwen, H. P.; J. Phys. Chem. A 2016, 120 , 8637.

54. Garces, J. L.; Mas, F.; Puy, J.; J. Chem. Phys. 2006, 124, 044710-1.

55. Puy, J.; Galceran, J.; Huidobro, C.; Companys, E.; Samper, N.; Garces, J. L.; Environ. Sci. Technol. 2008, 42, 9289.

56. Puy, J.; Huidobro, C.; David, C.; Rey-Castro, C.; Salvador, J.; Companys, E.; Colloids Surf., A 2009, 347, 156.

57. Rey-Castro, C.; Mongin, S.; Huidobro, C.; David, C.; Salvador, J.; Lluis, G. J.; Environ. Sci. Technol. 2009, 43, 7184.

58. David, C.; Mongin, S.; Rey-Castro, C.; Galceran, J.; Companys, E.; Garces, J. L.; Geochim. Cosmochim. Acta. 2010, 74, 5216.

59. Orsetti, S.; Andrade, E. M.; Molina, F. V.; J Colloid Interface Sci. 2009 , 336, 377.

60. Dryer, D. J.; Korshin, G. V.; Fabbricino, M.; Environ. Sci. Technol. 2008, $42,6644$.

61. Janot, N.; Reiller, P. E.; Korshin, G. V.; Benedetti, M. F.; Environ. Sci. Technol. 2010, 44, 6782.

62. Janot, N.; Reiller, P. E.; Zheng, X.; Croue, J. P.; Benedetti, M. F.; Water Res. 2012, 46, 731.

63. Yan, M.; Korshin, G. V.; Claret, F.; Croue, J. P.; Fabbricino, M.; Gallard, H.; Water Res. 2014, 59, 154.

64. Yan, M.; Dryer, D.; Korshin, G. V.; Chemosphere 2016, 148, 426.

65. Yan, M.; Wang, D.; Korshin, G. V.; Benedetti, M. F.; Water Res. 2013, 47, 2603.

66. Yan, M.; Benedetti, M. F.; Korshin, G. V.; Water Res. 2013, 47, 5439.

67. Yan, M.; Korshin, G. V.; Environ. Sci. Technol. 2014, 48, 3177.

68. Yan, M.; Li, D.; Gao, J.; Cheng, J.; Chemosphere 2014, 103, 290.

69. Chen, Y.; Fabbricino, M.; Benedetti, M. F.; Korshin, G. V.; Water Res. 2015, 68, 273.

70. Gao, Y.; Yan, M.; Korshin, G. V.; Environ. Sci. Technol. 2015, 49, 5905.

71. Marang, L.; Reiller, P. E.; Eidner, S.; Kumke, M. U.; Benedetti, M. F.; Environ. Sci. Technol. 2008, 42, 5094.

72. Janot, N.; Reiller, P. E.; Benedetti, M. F.; Colloids Surf., A 2013, 435, 9.

73. Kouhail, Y. Z.; Benedetti, M. F.; Reiller, P. E.; Environ. Sci. Technol. 2016, 50, 3706

74. Gondar, D.; Lopez, R.; Fiol, S.; Antelo, J. M.; Arce, F.; Eur. J. Soil. Sci. 2005, 56, 793.

75. Ge, Y.; Hendershot, W.; Soil. Sci. Soc. Am. J. 2004, 68, 82.

76. Lopez, R.; Gondar, D.; Antelo, J.; Fiol, S.; Arce, F.; Geoderma 2011 , $164,249$.

77. Lopez, R.; Gondar, D.; Antelo, J.; Fiol, S.; Arce, F.; Eur. J. Soil. Sci. 2012, 63, 487.

78. Plaza, C.; Brunetti, G.; Senesi, N.; Polo, A.; Environ Sci Technol. 2005 , 39,6692 .

79. Fernandez, J. M.; Plaza, C.; Senesi, N.; Polo, A.; Chemosphere 2007, 69,630 .

80. Van Zomeren, A.; Costa, A.; Pinheiro, J. P.; Comans, R. N. J. Environ. Sci. Technol. 2009, 43, 1393

81. Drosos, M.; Leenheer, J. A.; Avgeropoulos, A.; Deligiannakis, Y.; Environ. Sci. Pollut. Res. 2014, 21, 3963.

82. Maurer, F.; Christl, I.; Kretzschmar, R.; Environ. Sci. Technol. 2010, 44, 5787

83. Lamelas, C.; Benedetti, M.; Wilkinson, K. J.; Slaveykova, V. I.; Chemosphere 2006, 65, 1362.

84. Zhao, X. T.; Zeng, T.; Li, X. Y.; Gao, H. W. M.; J. Dispersion Sci. Technol. 2015, 36, 703.

85. Ederer, J.; Janos, P.; Ecorchard, P.; Stengl, V.; Belcicka, Z.; St'astny, M; React. Funct. Polym. 2016, 103, 44. 
86. Saito, T.; Terashima, M.; Aoyagi, N.; Nagao, S.; Fujitake, N.; Ohnuki, T.; Environ. Sci.: Processes Impacts 2015, 17, 1386.

87. Pedra, F.; Plaza, C.; Carlos, G. G. J.; Polo, A.; Bioresour. Technol. 2008, 99, 2141.

88. Sebastia, J.; Labanowski, J.; Lamy, I.; Chemosphere 2007, 68, 1245.

89. Tan, W.; Xiong, J.; Li, Y.; Wang, M.; Weng, L.; Koopal, L. K.; Colloids Surf., A 2013, 436, 1152.

90. Vidali, R.; Remoundaki, E.; Tsezos, M.; J. Colloid. Interface Sci. 2009, $339,330$.

91. Vasiliadis, B.; Antelo, J.; Iglesias, A.; Lopez, R.; Fiol, S.; Arce, F.; Eur. J. Soil. Sci. 2007, 58, 1358.

92. Weber, T.; Allard, T.; Tipping, E.; Benedetti, M. F.; Environ. Sci. Technol. 2006, 40, 7488.

93. Van Schaik, J. W. J.; Kleja, D. B.; Gustafsson, J. P.; Geochim. Cosmochim. Acta 2010, 74, 1391.

94. Gondar, D.; Iglesias, A.; Lopez, R.; Fiol, S.; Antelo, J. M.; Arce, F.; Chemosphere 2006, 63, 82.

95. Gondar, D.; Lopez, R.; Fiol, S.; Antelo, J. M.; Arce, F.; Geoderma 2006, 135,196 .
96. Villaverde, P.; Gondar, D.; Antelo, J.; Lopez, R.; Fiol, S.; Arce, F.; Eur. J. Soil Sci. 2009, 60, 377.

97. Ge, Y.; Hendershot, W.; Soil Sediment Contam. 2005, 14, 53.

98. Weng, L.; Van Riemsdijk, W. H.; Hiemstra, T.; Geochim. Cosmochim. Acta 2008, 72, 5857.

99. Xiong, J.; Koopal, L. K.; Tan, W.; Fang, L.; Wang, M.; Zhao, W.; Environ. Sci. Technol. 2013, 47, 11634.

100. Xu, J.; Tan, W.; Xiong, J.; Wang, M.; Fang, L.; Koopal, L. K.; J. Colloid. Interface Sci. 2016, 473, 141.

101. Christl, I.; Metzger, A.; Heidmann, I.; Kretzschmar, R.; Environ. Sci. Technol. 2005, 9, 5319.

102. Vidali, R.; Remoundaki, E.; Tsezos, M; Water, Air, Soil Pollut. 2011, $218,487$.

103. Christl, I.; Environ. Chem. 2012, 9, 89.

104. Maurer, F.; Christl, I.; Hoffmann, M.; Kretzschmar, R.; Environ. Sci. Technol. 2012, 46, 8808.

105. Hiemstra, T.; Van Riemsdijk, W. H.; Mar. Chem. 2006, 102, 181.

106. Gledhill, M.; Achterberg, E. P.; Li, K.; Mohamed, K. N.; Rijkenberg, M. J. A.; Mar. Chem. 2015, 177, 421. 